\title{
Numerical Study on Bubble Dynamics and Two-Phase Frictional Pressure Drop of Slug Flow Regime in Adiabatic T-junction Square Microchannel
}

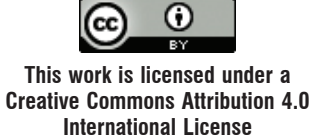
International License

\author{
K. Kishor, ${ }^{a}$ A. K. Chandra, ${ }^{a}$ W. Khan, ${ }^{a}$ P. K. Mishra, ${ }^{b}$ and M. Siraj Alam ${ }^{a,{ }^{*}}$ \\ aDepartment of Chemical Engineering, \\ doi: 10.15255/CABEQ.2016.877 \\ ${ }^{b}$ Department of Mechanical Engineering \\ Motilal Nehru National Institute of Technology Allahabad, \\ Allahabad-211004, U.P., India \\ Original scientific paper \\ Received: April 8, 2016 \\ Accepted: July 21, 2017
}

In this study, bubble dynamics and frictional pressure drop associated with gas liquid two-phase slug flow regime in adiabatic T-junction square microchannel has been investigated using CFD. A comprehensive study on the mechanism of bubble formation via squeezing and shearing regime is performed. The randomness and recirculation profiles observed in the squeezing regime are significantly higher as compared to the shearing regime during formation of the slug. Further, effects of increasing gas velocity on bubble length are obtained at fixed liquid velocities and simulated data displayed good agreement with available correlations in literature. The frictional pressure drop for slug flow regime from simulations are also obtained and evaluated against existing separated flow models. A regression correlation has also been developed by modifying $C$-parameter using separated flow model, which improves the prediction of two-phase frictional pressure drop data within slug flow region, with mean absolute error of $10 \%$. The influences of fluid properties such as liquid viscosity and surface tension on the two-phase frictional pressure drop are also investigated and compared with developed correlation. The higher liquid viscosity and lower surface tension value resulted in bubble formation via shearing regime.

Key words:

slug flow, two-phase frictional pressure drop, T-junction square microchannel

\section{Introduction}

Microfluidic systems offer opportunities for process automation as well as large-scale integration for chemical and biological systems. This holds potential for development of process intensification techniques such as Lab-on-a-Chip (LOC) and Micrototal-analysis-system ( $\mu$ TAS). Additionally, small sample sizes allow rapid, low cost, and highly sensitive analysis of chemical and biological samples in these systems ${ }^{1}$. The microfluidic system reduces transport distances and dilutions caused by Taylor dispersion. In addition, introduction of a new phase into these systems further reduces transport distances and dilutions caused by Taylor dispersion. Simultaneously, it increases the interfacial area and rate of self-mixing with formation of dispersions, bubble/droplets and films ${ }^{2}$. As a result, higher rate of heat and mass transfer is achieved in the multiphase microfluidic systems.

Many physical, chemical, and biological processes often involve gas liquid operations. Gas liq-

${ }^{*}$ Corresponding author: msalam@mnnit.ac.in uid two-phase flow in microfluidic systems provides efficient and economical stage for performing controlled fast reactions, mixing, separation, material synthesis, controlled generation and manipulation of dispersed micro-bubbles/droplets. Moreover, individual bubbles/droplets can be precisely generated, transported, sorted, mixed, controlled and analyzed. These micro-bubbles/droplets offer potential for compartmentalizing biological and chemical reactions within picolitre/nanolitre scale, similar to cellular levels. Further, these micro-bubbles/droplets have wide applications in the field of biomolecule synthesis, biomedical technology, diagnostics, drug delivery, and nanotechnology ${ }^{1}$.

Due to prevailing interfacial forces as compared to inertial forces, the physics of a microfluidic system differs significantly from macro-systems. The interfacial forces have significant influence on microfluidic multiphase flow behavior ${ }^{3}$. At present, the complex hydrodynamics, interaction between forces and relationships among different parameters in microfluidic systems are not universal and well established. Therefore, better insight on microfluid- 
Table 1 - Numerical studies on hydrodynamics, heat and mass transfer in slug flow in microfluidic devices based on VOF method

\begin{tabular}{|c|c|c|}
\hline Authors & Numerical dimensions/fluids & $\begin{array}{c}\text { Software/ } \\
\text { computational } \\
\text { domain }\end{array}$ \\
\hline Taha and $\mathrm{Cui}^{14}$ & $\begin{array}{l}\text { 2D; Circular, axial symmetry } \\
\text { geometry }(L \times 11 \mathrm{~L})\end{array}$ & $\begin{array}{l}\text { Fluent/ Moving } \\
\text { Frame }\end{array}$ \\
\hline $\begin{array}{l}\text { van Baten and } \\
\text { Krishna }^{23}\end{array}$ & $\begin{array}{l}2 \mathrm{D}, d: 1.5,2,3 \mathrm{~mm} \text {, axisymmetric } \\
\text { geometry }\end{array}$ & CFX/ Moving Frame \\
\hline
\end{tabular}

Key points

Bubble velocity, shape and velocity distribution around bubbles were investigated in slug flow and validated with past experimental results.

Volumetric mass transfer of liquid phase collectively influenced by bubble rise velocity, unit cell length, liquid diffusivity, length of liquid film, and the channel diameter.

Taha and $\mathrm{Cui}^{15} \quad 3 \mathrm{D}$, axisymmetric, Square Fluent/ Moving capillary, $L \times 11 \mathrm{~L} \quad$ Frame

Taha and $\mathrm{Cui}^{16} \quad$ 2D, Vertical capillary axisymmetric Fluent/ Moving geometry, $d \times 11 d \quad$ Frame

\section{Akbar and 2D, axisymmetric geometry Fluent/ moving \\ Ghiaasiaan $^{27} \quad d: 1 \mathrm{~mm} \quad$ Frame}

Qian and Lawal ${ }^{17}$ 2D, T-junction, $d$ : 0.25 to $3 \mathrm{~mm}$; Fluent/ Fixed Frame $L$ : $60 d$, Water and air

Kumar et al. ${ }^{18} \quad 3 \mathrm{D}$; Curved microchannels (mixed, Fluent/ Fixed Frame T- and Y-) of $d: 0.5 \mathrm{~mm}$, Water and air

Shao et al. ${ }^{28}$

$2 \mathrm{D}$, axisymmetric geometry, $d: 1$ $\mathrm{mm}$ with two gas nozzle sizes of 0.11 and $0.34 \mathrm{~mm} \mathrm{ID,} \mathrm{Air} \mathrm{and}$ three liquids (water, octane and semi-octane)

Liu and $\mathrm{Wang}^{24}$ square and equi-triangular capillaries; $d: 1 \mathrm{~mm} L: 16 d$

\section{Fluent/ Moving}

Frame

CFX/ Fixed Frame

The velocity distribution, shape and local wall shear stress around were investigated and validated with past experimental results.

The shape, velocity distribution and local wall shear stress were computed and validated with past experimental results.

Simulated bubble velocity, frictional pressure drop, slug length, and liquid film thicknesses compared reasonably well with literature.

Gas and liquid slug lengths obtained at various operating and fluid conditions. Slug lengths were found to be mainly dependent on phase hold-up. New correlations were proposed for estimating gas and liquid slug lengths.

For low curvature ratio non-uniformity in the slug formation was more pronounced as compared to the higher curvature ratios. Surface tension, viscosity and wall adhesion had major influence on slug flow development. Viscosity was more dominant in curved microchannels as compared to the straight microchannels.

Bubble formation mechanism and bubble size at different operating conditions and fluid properties was investigated. Increase in nozzle size and contact angles favor the formation of larger bubbles. Surface tension had higher influence on bubble size than viscosity and density.

Bubble size and shape, thickness of liquid film, velocity field and two-phase relative velocity were observed as functions of capillary number.

Guo and Chen ${ }^{19}$ 2D, rectangular geometry, $d: 200 \mu \mathrm{m}, L: 50 d$, Water and air

Fluent/ Fixed Frame

Bubble break-off mechanism at different Capillary number and influence of operating conditions and fluid properties was investigated. Gas slug length decreased with decreasing the surface tension and increased with decreasing of liquid viscosity.

Gupta et al..$^{20} \quad 2 \mathrm{D}$, axisymmetric circular geometry $d: 0.5 \mathrm{~mm}, L: 10 d$, Water and air

Dai et al. ${ }^{29}$

3D, T- type, Circular, $d: 100 \mu \mathrm{m}$, $L: 10 d$, Air and three liquids (water and semi-water)

Goel and Buwa ${ }^{30}$ 2D and 3D, axisymmetric, circular Fluent/ Fixed Frame microchannels $d: 0.3,0.5,0.75$, and $1 \mathrm{~mm}$, Water and air

Gupta et al. ${ }^{20}$

2D, axisymmetric simulations, $d: 0.5 \mathrm{~mm}, L: 15 d$, Water and air
Fluent/ Fixed Frame Liquid film was obtained using finer mesh near wall. Film thickness, gas holdup, bubble length and velocity and pressure distribution in a unit cell was studied.

Fluent/ Fixed Frame Three stages for bubble formation in squeezing regime were proposed via: expansion, collapse and pinching off. Collapse stage was found as most important stage in bubble formation process.

Effects of superficial gas and liquid velocities, channel geometry, wall adhesion, and fluid properties on the dynamics of bubble formation were investigated and validated with past experimental results.

Fluent and TransAT/ Volume of fluid (VOF) and level-set techniques of the Fixed Frame
ANSYS Fluent and TransAT codes, respectively was employed to study flow and heat transfer in slug flow regime. Both tools had similar results. 


\begin{tabular}{c|c|c|c}
\hline Authors & Numerical dimensions/fluids & $\begin{array}{c}\text { Software/ } \\
\text { computational } \\
\text { domain }\end{array}$ & Key points \\
\hline
\end{tabular}

Raj et al. ${ }^{31} \quad$ 3D, Rectangular, four different geometry, water and silicon oil
Santos and Kawaji ${ }^{21}$

Liu and Wang ${ }^{25}$ $3 \mathrm{D}, d_{\mathrm{H}}: 113 \mu \mathrm{m}$, nearly square Water and air

2D, Circular, axial symmetric, $d: 1 \mathrm{~mm}$.
Fluent/ Fixed Frame formation mechanism. Predicted drop/slug lengths were found to be independent of continuous phase viscosity, interfacial tension, channel size, inlet distributor for different values of Capillary numbers.

Fluent/ Fixed Frame

Good agreement with experimental value of gas slug length below $400 \mu \mathrm{m}$ was observed.

Fluent/ Moving Frame

Fluent/ Fixed Frame

\begin{tabular}{|c|c|}
\hline Kashid et $a l .^{32}$ & $\begin{array}{l}\text { 2D, T-type geometry, } \\
\text { Glycerol/water and } 3 \mathrm{M} \text { fluorinate } \\
\text { fluid FC-3283 and } 1 \mathrm{H}, 1 \mathrm{H}, 2 \mathrm{H}, 2 \mathrm{H} \\
\text { perfluoro-1-octanol }\end{array}$ \\
\hline Asadolahi et al. ${ }^{33}$ & $\begin{array}{l}\text { 2D, axisymmetric, vertically } \\
\text { upward, } d: 2 \mathrm{~mm}, L: 100 d \text { for } \\
\text { fixed frame and } 6.75 d \text { for movin } \\
\text { frame, Water and nitrogen }\end{array}$ \\
\hline Sivasamy et al. ${ }^{34}$ & $\begin{array}{l}3 \mathrm{D} \text {, rectangular microchannel } \\
\left(\mathrm{w} \times \mathrm{h}: 100 \times 200 \mu \mathrm{m}^{2} \text { and }\right. \\
L: 1000 \mu \mathrm{m}) \text {, Mineral oil } \\
\text { and DI water }\end{array}$ \\
\hline $\begin{array}{l}\text { Santos and } \\
\text { Kawaji }^{3}\end{array}$ & $\begin{array}{l}3 \mathrm{D}, d_{\mathrm{H}}: 113 \mu \mathrm{m} \text {, nearly square, } \\
\text { Water and air }\end{array}$ \\
\hline Li et $a l .{ }^{35}$ & $\begin{array}{l}\text { 3D, T-junction, rectangular; } \\
\text { aspect ratio- } 100 / 80 \mu \mathrm{m} \text {, Silicon } \\
\text { oil and aqueous glycerine }\end{array}$ \\
\hline
\end{tabular}

Horgue et al. ${ }^{36} \quad d: 2 \mathrm{~mm}, \mathrm{~L}: 10 \mathrm{~d}$

Fluent/ Moving

Frame and fixed

frame

Fluent/ Fixed Frame

Fluent/ Fixed Frame

Hydrophobic channels enhanced contact area of gas slugs with channel walls, whereas hydrophilic channels enhanced internal mixing within gas slugs and liquid plugs.

Fluent/ Fixed Frame Numerical and experimental analysis of mechanism of droplet formation in immiscible liquid/ liquid T-junction system. The experimental and numerical results displayed good agreement.

Fluent/ Fixed Frame Compared to Geo-Reconstruct, HRIC, QUICK, and CICSAM scheme using Fluent VOF method to provide computation speed and accuracy for simulation of the slug flow.

Talimi et al. ${ }^{26} \quad$ d: $0.5 \mathrm{~mm}$

$\begin{array}{ll}\text { Kang and } \mathrm{Zhou}^{39} & 3 \mathrm{D}, 594 \times 80 \mu \mathrm{m}^{2} \text {, serpentine } \\ \text { channel, } \mathrm{CO}_{2} \text { and methanol }\end{array}$

Chandra et $a l .{ }^{40} \quad 3 \mathrm{D}$, rectangular $\left(1.00 \times 1.00 \times 50 \mathrm{~mm}^{3}\right)$, Water-cyclohexane
Fluent/ moving and fixed frame of reference

Fluent/ Moving Frame

Open Foam/ Fixed Frame

Fluent/ Fixed Frame

Moving frame of reference method over predicted pressure drop and heat transfer.

Heat transfer inside square microchannel under constant wall temperature boundary condition in twophase slug flows was simulated at different Reynolds number, contact angle, and slug length.

Presented criteria for optimizing computational settings for observing and studying film and bubble dynamics in segmented flow.

Studied effects of surface tension and viscosity on the bubble generation process in direct methanol fuel cells (DMFC).

Fluent/ Fixed Frame Less number of slugs formed for small values of obstruction spacing and inducing more internal mixing within a slug. 
ic systems is required in order to broaden the existing knowledge and expertise on these systems.

In the literature, numerous experimental investigations are reported on the hydrodynamics and flow characteristics of gas liquid two-phase flow in microfluidic systems over the years ${ }^{4-13}$. Several flow patterns such as bubbly, slug/Taylor, churn, annular and dispersed have been observed in the gas liquid two-phase flow. These flow patterns develop in different flow conditions, fluid's nature, channel size, geometry and wettability of the microfluidic system. The flow pattern maps ${ }^{4,7,8,10}$ indicate that slug flow usually dominates over other flow patterns for wide-ranging operating conditions in microfluidic systems. The slug flow is characterized by alternate sequences of cylindrical shaped liquid slugs and gas bubbles. The diameter of the bubbles is in range of the hydraulic diameter of channel or greater. These gas bubbles fill the entire cross section of the channel with thin film of the liquid separating bubbles from the wall of channel. Slug flow provides enhanced stability, control, safety, higher heat and mass transfer rate due to reduced axial distance, higher radial mixing, and large interfacial area.

\section{Numerical studies on microfluidic slug flow}

The continuous evolution and advancement in the field of efficient multiphase flow modelling, interface capturing, pre-processor, solver and post-processing techniques have made CFD codes/ software a powerful tool for analysing and designing systems which involve fluid flow, heat and mass transfer. The numerical studies in the field of the microfluidic flow are increasing rapidly as they may provide detailed, precise and reliable information on parameters as compared to experimental results which are uneconomical and often erroneous. Interface tracking techniques such as volume of fluid (VOF) method is one of the popular ways for tracking interfaces in multiphase flow. Recently, many authors had examined hydrodynamics, flow characteristics and related parameters of the slug flow in microfluidic systems using VOF method. Mostly, fixed and moving frame computational domains were employed to simulate slug flow using VOF methods in these studies.

Taha and Cui ${ }^{14-16}$ applied control volume method using VOF method and studied hydrodynamics of slug flow in terms of velocity field, wall shear stress distribution, bubble shape and velocity profile at different capillary numbers in two-dimensional capillary and three-dimensional square capillary with refined grid near wall by means of moving frame simulation. The simulated results of bubble shape, wall shear stress and velocity profiles were in good agreement with previous experimental results. In another benchmark study, Qian and Law$\mathrm{al}^{17}$ investigated Taylor flow in T-junction microchannel using VOF method with varying cross sections of the channel ranging from $0.25 \mathrm{~mm}$ to 3 $\mathrm{mm}$ in fixed frame two-dimensional geometry. They reported gas and liquid slug length at various flow rates, diameters, fluid properties and inlet configurations. The gas and liquid slug lengths were increased with increase in their respective fluid velocity, and dimensionless slug sizes $\left(L_{g} / d\right.$ and $L / d$ ) were found to be mainly dependent on phase hold up. Liquid viscosity had no major impact on slug lengths, whilst the surface tension and wall adhesion affected slug lengths moderately. In addition, non-uniformity in slug size increased with increasing fluid velocity. Kumar et al. ${ }^{18}$ studied Taylor flow in curved microreactors at different operating conditions and reported influences of the inlet geometry conditions, flow rates, channel diameters, curvature ratio, inlet volume fraction, wall contact angle and fluid properties on slug length. They observed that the effect of fluid viscosity was more pronounced in curved microchannels than straight microchannels. Guo and Chen ${ }^{19}$ studied the mechanism of bubble formation, effect of capillary number, gas and liquid velocity, contact angles and fluid properties on the slug lengths. The squeezing regime was reported on low $C a$ number while shearing regime was found at high $\mathrm{Ca}$ number. Also, for the formation of the bubbles, a threshold value of wall contact angle for different capillary number was proposed. Gupta et al. ${ }^{20}$ carried out CFD simulation of Taylor flow in circular channel of diameter $0.5 \mathrm{~mm}$ and length of $10 \mathrm{~d}$ having air and water as the working fluids using commercial software Fluent. The VOF method, CSF method and QUICK scheme were adopted and suggested the use of finer mesh near the wall in order to capture wall liquid film. Santos and Kawaji ${ }^{21,22}$ compared void fraction and slug length of the gas liquid system in nearly square-shaped T-junction microchannel of hydraulic diameter $113 \mu \mathrm{m}$ experimentally and numerically. The void fraction predicted numerically had linear relationship with homogeneous void fraction while values obtained experimentally depend upon ratio of superficial velocities $\left(U_{g} / U_{l}\right)$. The simulated gas slug length was similar in size to that obtained experimentally for slug length less than $400 \mu \mathrm{m}$ while they were dissimilar for longer slug sizes. In few other numerical studies, heat and mass transfer in microfluidic devices were also investigated ${ }^{23-26}$. A comprehensive summary of numerical studies based on VOF model in two-phase microfluidic flow is presented in Table 1. However, numerical studies have not been reported so far on the modelling of 
two-phase frictional pressure drop in microfluidic devices employing CFD. As a result, an attempt has been made in the present study to investigate bubble dynamics and two-phase frictional pressure drop associated with slug flow regime for adiabatic T-junction square microchannel using CFD.

\section{Numerical methodology}

\section{Model geometry}

In the present investigation, a T-junction square microchannel having hydraulic diameter $\left(d_{H}\right) 1 \mathrm{~mm}$ is initially prepared and meshed in ANSYS. The fluid inlets are constructed at an angle of $90^{\circ}$. The lengths of square-shaped fluid inlets are $2 \mathrm{~mm}$. The length of mixing zone is kept $150 \mathrm{~mm}$ long, so that the mixing effect of two fluids can be easily captured, and the fully developed flow can be observed. The longer channel length also enabled observing stability and uniformity of bubble size at several flow conditions. The three-dimensional T-junction microchannel is shown in Fig. 1. The water and air are taken as working fluids. The fluids are fed separately through two different inlets of T-junction to mixing zone. The water is fed horizontally while gas is introduced vertically into the channel. The physical properties of fluids used in the present simulation are mentioned in Table 2.

\section{Governing equations}

The volume of fluid (VOF) method ${ }^{41}$ has been adopted for tracking locations of interface between gas and liquid phases by solving additional continuity equation for volume fraction for one of the phases. In the VOF method, two or more phases are considered as immiscible and for each control volume, the volume fractions of all phases sum up to unity. For each additional fluid phase, i, introduced in the system, a new volume fraction term $\left(\alpha_{\mathrm{i}}\right)$ is added as a variable in the computational cell, i.e.

$-\alpha_{\mathrm{i}}=0$ : the cell is empty of the $\mathrm{i}^{\text {th }}$ phase.

$-\alpha_{\mathrm{i}}=1$ : the cell is full of the $\mathrm{i}^{\text {th }}$ phase.

$-0<\alpha_{i}<1$ : the cell contains the interface between the $i^{\text {th }}$ phase and one or more other phases.
Table 2 -Physical properties of fluids used in the present simulation

\begin{tabular}{c|c|c|c}
\hline Fluid & $\rho\left(\mathrm{kg} \mathrm{m}^{-3}\right)$ & $\mu\left(\mathrm{kg} \mathrm{m}^{-1} \mathrm{~s}^{-1}\right)$ & $\sigma\left(\mathrm{N} \mathrm{m}^{-1}\right)$ \\
\hline Air & 1.225 & $1.7894 \cdot 10^{-5}$ & - \\
Water & 998.2 & 0.001003 & 0.072 \\
\hline
\end{tabular}

A single set of the continuity and momentum equations is solved throughout the computational domain. The continuum surface force (CSF) mod$\mathrm{el}^{42}$ is employed to model surface tension as an extra body force in momentum equation. The continuity and momentum equation of the VOF formulations of two-phase flow are as follows:

Equation of continuity:

$$
\frac{\partial \rho}{\partial t}+\nabla \cdot(\rho \vec{v})=0
$$

Equation of motion:

$\frac{\partial(\rho \vec{v})}{\partial t}+\nabla \cdot(\rho \vec{v} \vec{v})=\Delta p+\Delta \cdot\left[\mu\left(\nabla \vec{v}+\nabla \vec{v}^{T}\right)\right]+\rho \vec{g}+\vec{F}$

Volume fraction equation:

$$
\frac{\partial \alpha_{g}}{\partial t}+\vec{v} \nabla \alpha_{g}=0
$$

where,

$$
\begin{aligned}
& \rho=\alpha_{l} \rho_{l}+\alpha_{g} \rho_{g} \\
& \mu=\mu_{l} \rho_{l}+\mu_{g} \rho_{g}
\end{aligned}
$$

\section{Simulation schemes}

The simulations are performed in ANSYS FLUENT 15.0 release using double-precision solvers with fixed frame 3D computational domain. Before simulation process, grid independency tests are conducted to ensure optimum mesh spacing. As the present study is primarily focussed on investigation of two-phase frictional pressure drop in slug flow region, the cell numbers are increased until the data obtained for two-phase frictional pressure drop are grid independent. Different cell numbers ranging from 153000 to 425456 were used for this purpose. The present computational geometry contains 298753 hexahedral cells. The courant number is

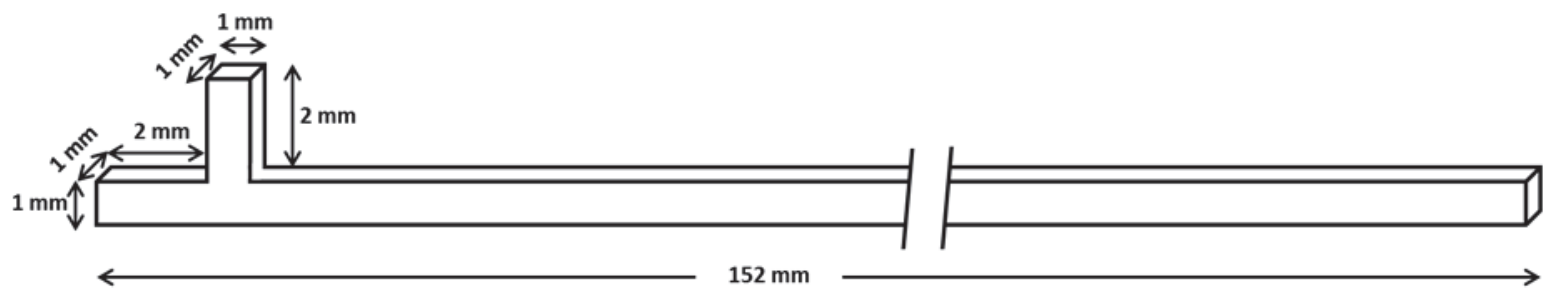

Fig. 1 - Schematic representation of the T-junction square microfluidic test section of $d_{H}=1 \mathrm{~mm}$ 
fixed at 0.25 and time step size is in order of $10^{-5} \sim 10^{-6}$ second in present simulations. The wall adhesion is turned on and the contact angle is kept at default condition at $90^{\circ} .{ }^{18}$ The surface tension value is kept at $0.072 \mathrm{~N} \mathrm{~m}^{-1}$. The no-slip walls condition is applied. Water is assigned as primary phase and air as secondary phase. Pressure-implicit with staggering option (PISO) scheme is selected for the pressure velocity coupling, with neighbour correction value as one. For the spatial discretization, green gauss cell based method for gradient, Pressure staggering option (PRESTO!) scheme for pressure, second order upwind scheme for momentum equation with geo-Reconstruct scheme for volume fraction were adopted as solution methods. The transient formulation first order implicit with non-iterative time advancement is set in current simulation. For slug flow region, gas and liquid flow rates ranges were adopted from the flow regime map of ${ }^{4}$. The flow rates of both gas and liquid used in the present simulation ranged from $0.025-0.5 \mathrm{~m} \mathrm{~s}^{-1}$. The flow conditions are laminar and capillary number is in the range of $10^{-4}-10^{-2}$ in all simulations. The scaled residual for continuities and velocities ranged around $10^{-4}$ and $10^{-8}$, respectively, under these conditions.

\section{Results and discussion}

\section{Effect of capillary number on bubble formation}

Capillary number $(\mathrm{Ca})$ is defined as the ratio of viscous to interfacial forces. It is an important dimensionless number, used to characterize two-phase flow behavior in microfluidic devices and can be represented by the following correlation:

$$
C a=\mu U_{b} / \sigma
$$

The value of $C a$ lies typically in the range of $10^{-4}-10^{-2}$ for microfluidic devices as reported by Garstecki et al. ${ }^{43}$ The authors studied the process of droplet and bubble formation in microfluidic T-junctions geometry using the liquid-liquid two-phase flow system and divided bubble formation mechanism into two regimes, i.e., squeezing and shearing regime. The squeezing regime is observed at low capillary number where interfacial forces were dominant and formation of bubbles were not dominated by shear stresses; rather it emerged from pressure drop across the emerging bubbles. At high capillary number, shear forces come into play and the formation of bubbles get dominated by shearing stresses of continuous phase which shear off the emerging bubbles. Van Steijn et $a l .{ }^{44}$ and Guo and Chen ${ }^{19}$ also observed and confirmed bubble formation mechanism through squeezing and shearing regime using experimental and numerical investiga- tions in microfluidic devices. Their studies showed that the formation of bubbles mainly depends on the ratio of fluid flow rate and channel dimension. The typical values of capillary number for transition between these two regimes are in the order of $10^{-3}$.

In the present study, the effects of capillary number on the bubble formation mechanism are studied. The squeezing regimes are observed at low capillary numbers $\left(10^{-4} \sim 1.5 \cdot 10^{-3}\right)$ and shearing regimes appeared at high capillary numbers $\left(1.5 \cdot 10^{-3}\right.$ $\sim 10^{-2}$ ) in slug flow region, as shown in Figs. 2 and 3 . In addition, the bubble formation followed shearing regime only with increase in velocity of continuous phase (water) and remained almost unaffected by increasing velocity of the dispersed phase (gas). During simulations, a higher degree of randomness and recirculation is observed near gas liquid interface in the squeezing regime compared to the shearing regime, as illustrated by the velocity vectors in Figs. 2 and 3 respectively. In shearing regime, fluids velocity vectors are moving parallel to each other in both phases under the influence of shearing forces. While, in squeezing regime, chaotic movements of velocity vectors are observed. Also, mixing is decreased along the direction near to wall. Hence, the observed rate of mixing between fluids is higher in squeezing regimes in two-phase microfluidic flow.

\section{Effect of flow rates on bubble length}

The bubble/droplet length is an important parameter in slug flow characterization and is crucial for determination of mass transfer in the microfluidic devices ${ }^{45,23,46,47}$. The bubble lengths are a function of channel diameter, gas/ liquid flow rates, and their physical properties. Some previous investigators had studied bubble length and proposed correlations which are listed in Table 3.

In the present investigation, the effect of increasing gas velocity on bubble length is studied at a fixed liquid velocity of $0.05 \mathrm{~m} \mathrm{~s}^{-1}$. The simulated results are plotted and compared with available correlations of Qian and Lawal ${ }^{17}$, van Steijn et al. ${ }^{44}$, Pohorecki and Kula ${ }^{48}$, Sobieszuk et al. ${ }^{49}$ and Kawahara et al. ${ }^{12}$ as shown in Fig. 4. It is clearly evident from the figure that the bubble length increases with increase in gas velocity at a fixed liquid velocity, and this trend continues to the boundaries of the slug flow regime. On further increase in gas velocity, the channel becomes entirely filled with the gas phase. In addition, the trend obtained is similar to that predicted by previous correlations Eq. (7-10). The correlations proposed by Pohorecki and Kula ${ }^{48}$ and Kawahara et al. ${ }^{12}$ matched with simulated data very closely. The result indicates that bubble lengths are primarily a function of channel diameter and ratio of gas to liquid flow rates. Further, at low value 

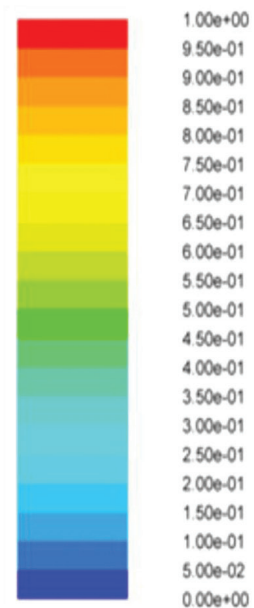

Fig. 2 - Slug formation in squeezing regime at $U_{g}=0.025 \mathrm{~m} \mathrm{~s}^{-1}$ and $U_{l}=0.025 \mathrm{~m} \mathrm{~s}^{-1}$ at $\mathrm{Ca}=6.965 \cdot 10^{-4}$ as shown by velocity vectors (air: red velocity vectors; water: blue velocity vectors)
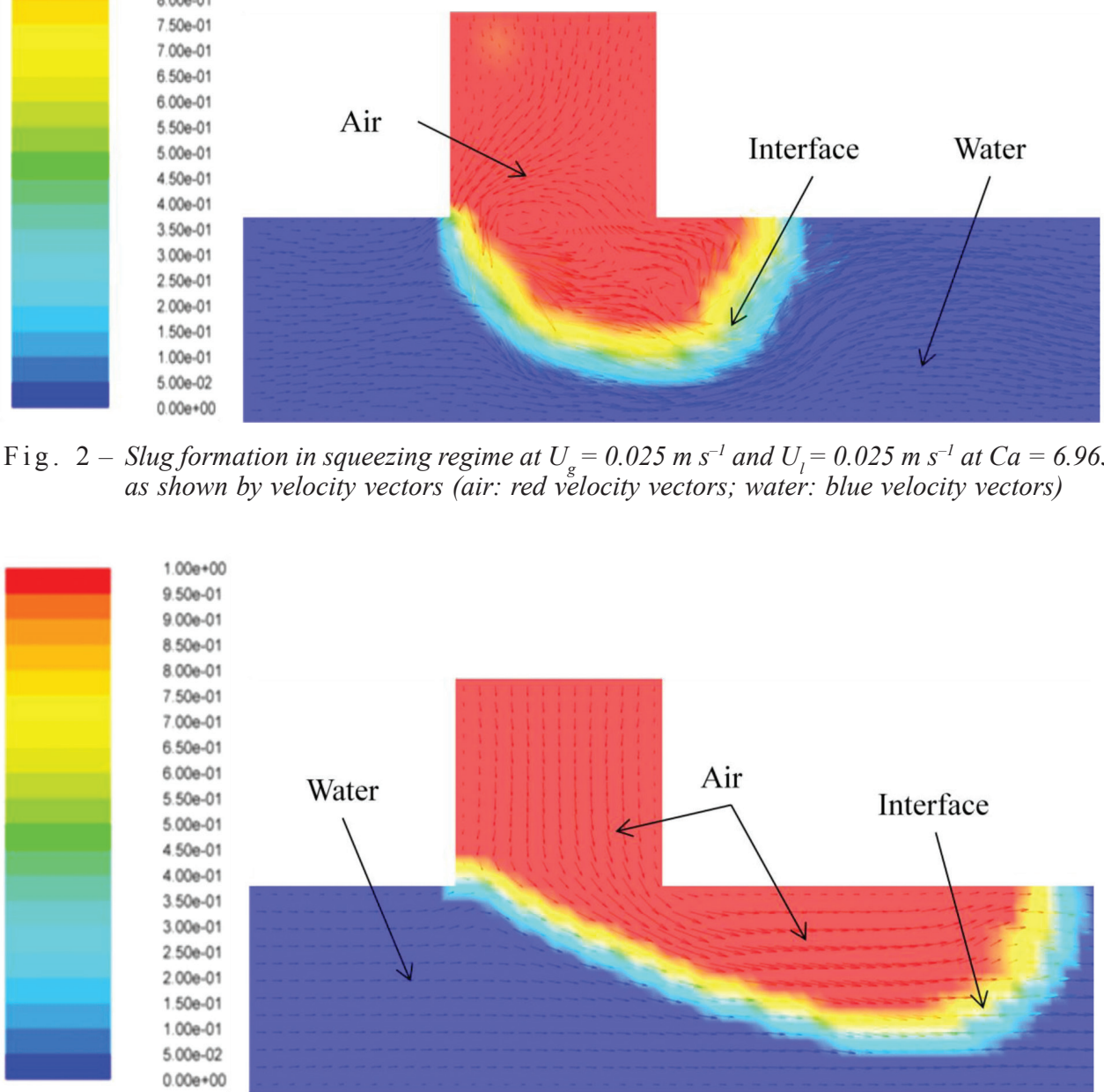

Fig. 3 - Slug formation in shearing regime at $U_{g}=0.2 \mathrm{~m} \mathrm{~s}^{-1}$ and $U_{l}=0.2 \mathrm{~m} \mathrm{~s}^{-1}$ at $C a=5.5722 \cdot 10^{-3}$ as shown by velocity vectors (air: red velocity vectors; water: blue velocity vectors)

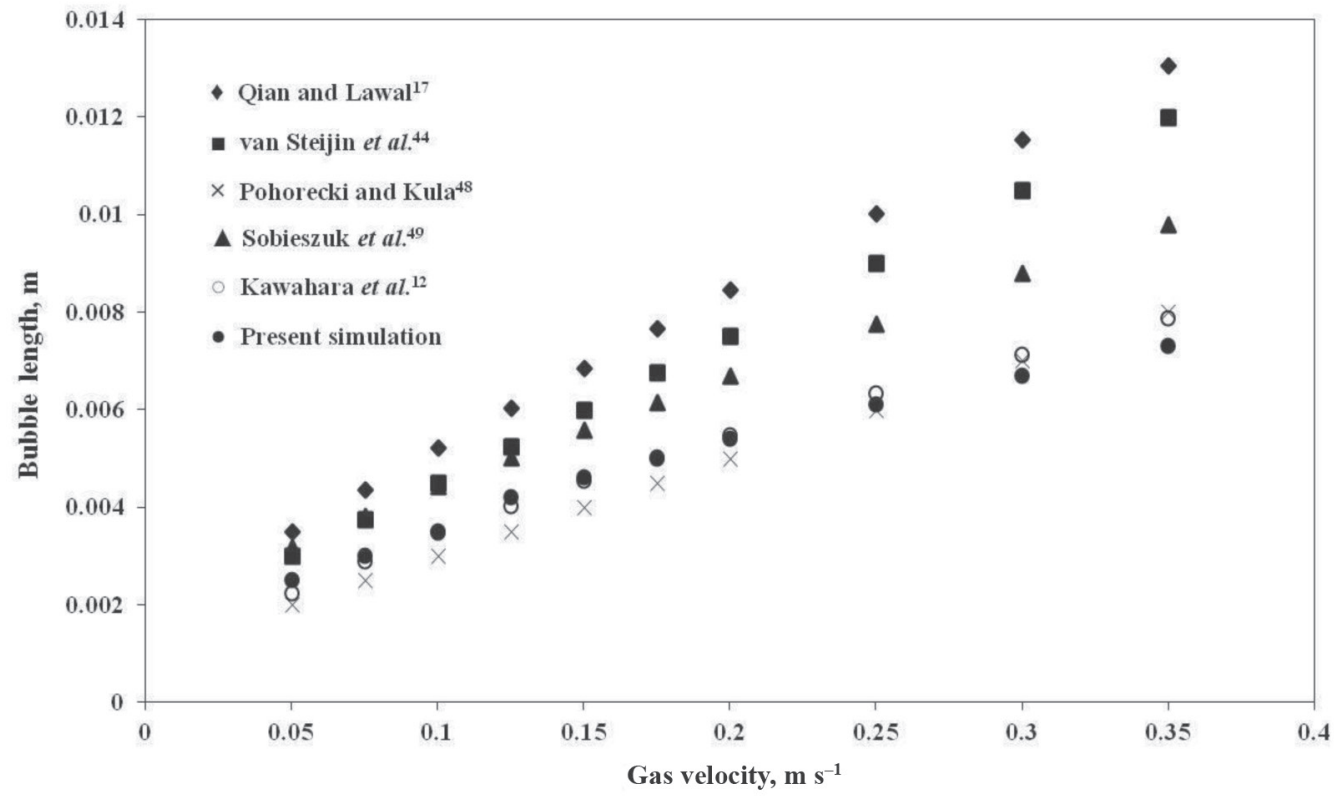

Fig. 4 -Variation of bubble length with increasing gas velocity at fixed liquid velocity $U_{1}=0.05 \mathrm{~m} \mathrm{~s}^{-1}$ 
Table 3 -Correlation of bubble length proposed in literature

\begin{tabular}{|c|c|c|}
\hline Authors & Correlation of bubble length & Experimental conditions \\
\hline Qian and Lawal'17 & $\begin{array}{l}\frac{L_{g}}{d_{\mathrm{H}}}=1.637 \varepsilon_{g}^{0.107}\left(1-\varepsilon_{g}\right)^{-1.05} R e^{-0.075} C a^{-0.0687} \\
\text { where, } R e=\frac{\rho_{l} U_{T P} d}{\mu_{l}}, C a=\frac{\mu_{l} U_{T P}}{\sigma} \text { and } \varepsilon_{g}=\frac{U_{g}}{U_{g}+U_{l}}\end{array}$ & $\begin{array}{l}\text { Numerical investigation with T-junction microchannel } \\
\text { with } d=0.25,0.5,0.75,1,2 \text { and } 3 \mathrm{~mm} \text { using air and } \\
\text { water. }\end{array}$ \\
\hline van Steijn et al. ${ }^{44}$ & $\begin{array}{l}\frac{L_{g}}{d_{\mathrm{H}}}=\alpha_{1}+\alpha_{2} \frac{U_{g}}{U_{l}} \\
\text { where } \alpha_{1} \text { and } \alpha_{2} \text { are dimensionless parameters } \\
\left(\alpha_{1}=\alpha_{2}=1.5\right)\end{array}$ & $\begin{array}{l}\text { Square T-junction microchannel of } d_{\mathrm{H}}=800 \mu \mathrm{m} \text { using } \\
\text { ethanol and air as working fluids. }\end{array}$ \\
\hline Pohorecki and Kula ${ }^{48}$ & $\frac{L_{g}}{d_{\mathrm{H}}} \sim 1+\frac{U_{g}}{U_{l}}$ & $\begin{array}{l}\text { Different Y- shaped microreactors (PDMS: polydimeth- } \\
\text { yloxosilane } 150 \mu \mathrm{m} \times 150 \mu \mathrm{m} \text {, and glass } 400 \mu \mathrm{m} \text { dia) } \\
\text { using ethanol-nitrogen system. }\end{array}$ \\
\hline Sobieszuk et al. ${ }^{49}$ & $\frac{L_{g}}{d_{\mathrm{H}}}=1.3 \varepsilon_{g}^{0.007}\left(1-\varepsilon_{g}\right)^{-1.01} W e^{-0.1}$ & $\begin{array}{l}\text { Y-junction straight microchannels with } d_{\mathrm{H}}=0.15,0.29 \\
\text { and } 0.4 \mathrm{~mm} \text { using four different liquids. }\end{array}$ \\
\hline Kawahara et al. ${ }^{12}$ & $\frac{L_{g}}{d_{\mathrm{H}}}=2.22\left(\frac{U_{g}}{U_{l}}\right)^{0.65}$ & $\begin{array}{l}\text { Horizontal rectangular T-junction microchannel } \\
\left(d_{\mathrm{H}}=0.235 \mathrm{~mm}\right) \text { with distilled water, ethanol, and } \\
\text { HFE7200 as liquid phase and nitrogen as gas phase. }\end{array}$ \\
\hline
\end{tabular}

of capillary number, the bubble sizes are uniform along the length of the channel; however, increasing liquid velocity induced non-uniformity in the bubble sizes in the channel. In the present study, the non-uniformity was observed near $\mathrm{Ca} \sim 1.5 \cdot 10^{-3}$. Therefore, more controlled and uniformly sized bubbles can be generated in the squeezing regime (Fig. 5)

\section{Two-phase frictional pressure drop in slug flow regime}

An extensive knowledge of flow regimes, pressure drop and void fraction is required in design, development and control of the microfluidic devices. In the adiabatic two-phase horizontal flow, the total pressure drop considerably depends on frictional pressure drop. In recent times, separated flow model has been employed more frequently to model two-phase frictional pressure drop in microfluidic devices. In separated flow models, it is assumed that each phase flows separately with different velocity and with their actual properties in its section of the channel. The frictional pressure gradient can be calculated using the two-phase frictional multiplier, $\phi_{l}^{2}$, and the Martinelli parameter, $X^{2}$, as follows:

$$
\left(\frac{\mathrm{d} p}{\mathrm{~d} z}\right)_{f}=\left(\frac{\mathrm{d} p}{\mathrm{~d} z}\right)_{l} \phi_{l}^{2}
$$

where

$$
\phi_{l}^{2}=1+\frac{C}{X}+\frac{1}{X^{2}}
$$

and

$$
X^{2}=\left(\frac{\mathrm{d} p}{\mathrm{~d} z}\right)_{l} /\left(\frac{\mathrm{d} p}{\mathrm{~d} z}\right)_{g}
$$

where $(\mathrm{d} p / \mathrm{d} z)_{l}$, and $(\mathrm{d} p / \mathrm{d} z)_{g}$ are frictional pressure drop gradients when liquid and gas are assumed to flow in the channels alone, respectively. On the right-hand side of Eq. 6, "l" represents liquid-only pressure drop, " $1 / X^{2}$ " represents gas-only pressure drop, and " $C / X$ " represents interaction between liquid phase and gas phase. The parameter " $C$ " represents the interactional effect of the two-phase flow, which is a function of gas-liquid system and

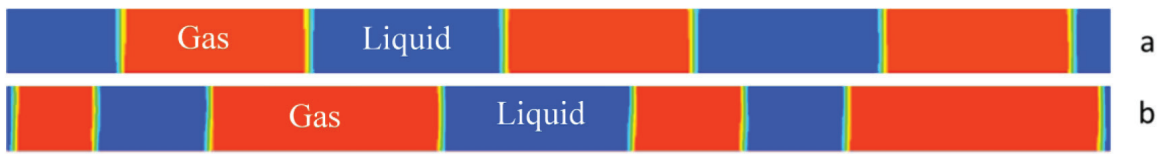

Fig. 5 - Non-uniformity in bubble length during flow in channel of the squeezing and shearing regime (a) at $U_{g}=0.1 \mathrm{~m} \mathrm{~s} \mathrm{~s}^{-1}$ and $U_{l}=0.1 \mathrm{~m} \mathrm{~s}^{-1}$ and (b) $U_{g}=0.2 \mathrm{~m} \mathrm{~s}^{-1}$ and $U_{l}=0.2 \mathrm{~m} \mathrm{~s}^{-1}$ 
Table 4 -Correlations available in literature for $C$ - and $\Phi^{2}$ parameter according to various authors

\begin{tabular}{|c|c|c|}
\hline Author(s) & $\begin{array}{l}\text { Separated flow model, } \\
C \text {-parameter and } \Phi^{2}\end{array}$ & Remarks \\
\hline $\begin{array}{l}\text { Lockhart and } \\
\text { Martinelli }\end{array}$ & $C=5$, for laminar-laminar gas liquid flow & $d_{\mathrm{H}}=1.49-25.83 \mathrm{~mm}$, adiabatic, water, oils, hydrocarbons \\
\hline $\begin{array}{l}\text { Müller-Steinhagen } \\
\text { and Heck }{ }^{51}\end{array}$ & $\begin{array}{l}(\mathrm{d} P / \mathrm{d} z)_{f}=M(1-x)^{1 / 3}+B x^{3} \\
\text { where, } M=A+(B-A) x\end{array}$ & Developed using 9300 data points collected from literature \\
\hline Mishima and Hibiki ${ }^{51}$ & $\begin{array}{l}\text { For rectangular channel } \\
C=21\left(1-e^{-0.333 d_{\mathrm{H}}}\right) \\
\text { For circular channel } \\
C=21\left(1-e^{-0.319 d_{C}}\right)\end{array}$ & $d_{\mathrm{H}}=1.05-4.08 \mathrm{~mm}$, adiabatic, air-water \\
\hline Lee and $\mathrm{Lee}^{53}$ & $\begin{array}{l}C=A \lambda^{q} \psi^{r} R e_{l}^{s} \\
\text { where, } \psi=\frac{j \mu_{l}}{\sigma} \text { and } \lambda=\frac{\mu_{l}^{2}}{\rho_{l} \sigma d}\end{array}$ & $d_{\mathrm{H}}=0.78-6.67 \mathrm{~mm}$, adiabatic, air-water \\
\hline Zhang et al. ${ }^{54}$ & $\begin{array}{l}C=21\left(1-e^{-0.674 / L o}\right) \\
\text { where, } L o=\left\{\frac{\sigma}{g\left(\rho_{l}-\rho_{g}\right)}\right\}^{0.5} / d_{\mathrm{H}}\end{array}$ & Developed using 2201 data points collected from literature \\
\hline Hwang and $\mathrm{Kim}^{55}$ & $C=0.227 \operatorname{Re}_{l o}^{0.452} X^{-0.32} L o^{-0.82}$ & $d_{\mathrm{H}}=0.244,0.430,0.792 \mathrm{~mm}$, adiabatic \\
\hline $\begin{array}{l}\text { Saisorn and } \\
\text { Wongwises }^{8}\end{array}$ & $\phi^{2}=1+6.627 / X^{0.761}$ & $d_{\mathrm{H}}=0.53 \mathrm{~mm}$, air-water \\
\hline Kawahara et al. ${ }^{11}$ & $C=1.38 B o^{0.04} \operatorname{Re}_{l}^{0.25} W e_{g}^{-0.12}$ & $\begin{array}{l}d_{\mathrm{H}}=0.235 \mathrm{~mm} \text { with distilled water, ethanol, and HFE7200 as } \\
\text { liquid phase and nitrogen as gas phase }\end{array}$ \\
\hline $\begin{array}{l}\text { Saisorn and } \\
\text { Wongwises }^{9}\end{array}$ & $C=7.599 \cdot 10^{-3} \lambda^{-0.631} \psi^{0.005} \operatorname{Re}_{l o}^{-0.008}$ & $d_{\mathrm{H}}=0.53,0.22$ and $0.15 \mathrm{~mm}$, air-water \\
\hline $\mathrm{Li}$ and $\mathrm{Wu}^{56}$ & $\begin{array}{l}C=11.9 B o^{0.45} \text { for } B o \leq 1.5 \\
C=109\left(B o R e_{l}^{0.5}\right)^{-0.56} \text { for } 1.5<B o \leq 11\end{array}$ & Developed using 769 data points collected from literature \\
\hline Kim and Mudawar ${ }^{57}$ & $\begin{array}{l}\text { For the laminar-laminar gas liquid flow } \\
C=3.5 \cdot 10^{-5} R e_{l o}^{0.44} S u_{g o}^{0.50}\left(\frac{\rho_{l}}{\rho_{g}}\right)^{0.48}\end{array}$ & Developed using 7115 data points collected from literature \\
\hline
\end{tabular}

flow conditions. Several investigators have proposed different correlations by modifying $C$ - and $\Phi^{2}$ parameters. Some of these correlations are listed in Table 4.

Also, Kruetzer et al. ${ }^{58}$ proposed frictional pressure drop model by modifying friction factor $\left(f_{R e}\right)$.

$$
f_{R e}=\frac{16}{R e}\left[1+\frac{0.17 d}{l_{s}}\left(\frac{R e}{C a}\right)^{1 / 3}\right]
$$

However, the shortcoming of this equation is that it needs information about slug length $\left(l_{s}\right)$. The determination of slug length requires the use of sophisticated technologies such as high speed camera, lenses, and careful examination. Moreover, the slug lengths may vary with flow conditions and are non-uniform in shearing flow regime. In such cases, the application of the above model, which requires slug length to predict two-phase frictional pressure drop of entire channel, will be quite a puzzling task. In this regard, prediction of the frictional pressure drop in microfluidic system is better with separated flow model, which requires information regarding physical properties and flow rates of the fluids only.

\section{Evaluation of existing correlations of two-phase frictional pressure drop for slug flow}

The previous investigations for prediction of the two-phase frictional pressure drop in microfluidic devices have largely been experimental and no attempts have been made so far to study this problem by numerical simulation. In the present study, the two-phase frictional pressure drop associated 


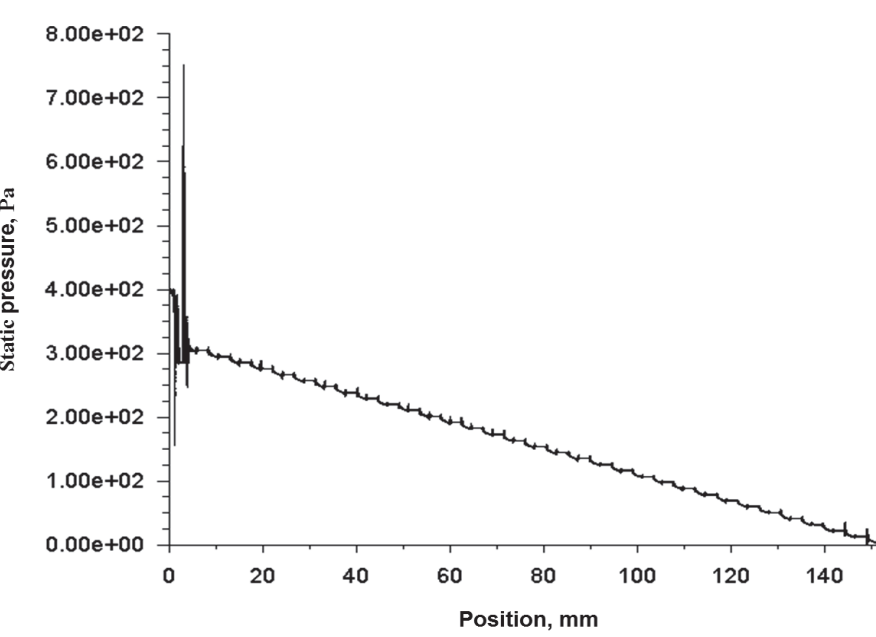

Fig. 6 - Static pressure behaviour along the flow domain of channel in fully developed slug flow (at $U_{g}=0.05$ $\mathrm{ms}^{-1}$ and $U_{1}=0.05 \mathrm{~m} \mathrm{~s}^{-1}$ )

with slug flow regime in adiabatic T-junction square microchannel by numerical simulation has been investigated. Upon the completion of each simulation, the static pressure is recorded at two different locations, fixed along channel length for the measurement of frictional pressure drop. The difference in the static pressure between two locations is divided by distance between points to find frictional pressure drop ${ }^{22}$.

$$
\left(\frac{\mathrm{d} p}{\mathrm{~d} Z}\right)_{T P} \cong\left(\frac{\Delta p}{\Delta Z}\right)_{T P}=\frac{p_{x_{1}}-p_{x_{2}}}{x_{2}-x_{1}}
$$

The static pressure behaviour along the flow domain of channel in fully developed slug flow is illustrated in Fig. 6. A sharp rise in static pressure is

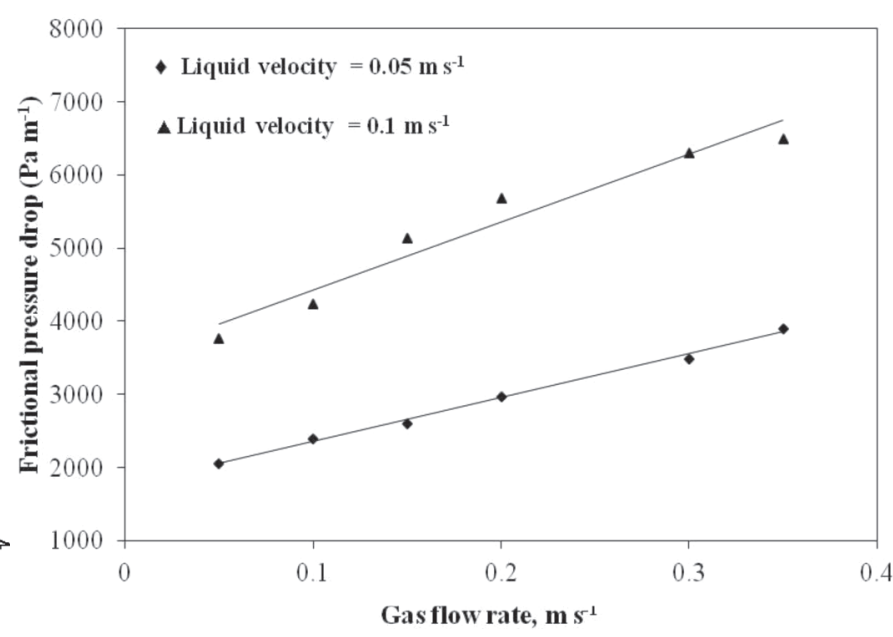

Fig. 7 - Variation of the two-phase frictional pressure drop with increasing gas velocity at fixed liquid velocity

observed at the T-junction due to interaction between two fluids. Also, pressure is higher at gas-liquid interface than the pressure of both neighbour phases. The two-phase frictional pressure drop data as a function of gas liquid flow rates in the microchannel is plotted in Fig. 7. The two-phase frictional pressure drop data obtained in this simulation is found to increase with increasing fluid velocities similar in many other studies ${ }^{6,5,47}$. The simulated data are also compared with the data obtained with the available correlation of Lockhart and Martinelli ${ }^{50}$, Mishima and Hibikis2, Zhang et al. ${ }^{54}$, Müller-Steinhagen and $\mathrm{Heck}^{51}$, Lee and $\mathrm{Lee}^{53}$, Hwang and $\mathrm{Kim}^{55}$, Saisorn and Wongwises ${ }^{8,9}$, Li and $\mathrm{Wu}^{56}$, Kawahara et al. ${ }^{11}$, Kim and Mudawar ${ }^{57}$.

Table 5 - Mean absolute error (MAE) of numerical data with existing literature correlations

\begin{tabular}{|c|c|c|c|}
\hline Authors & $\begin{array}{l}\text { Mean Absolute Error } \\
\text { (MAE) \% }\end{array}$ & $\begin{array}{l}\text { Maximum deviation from } \\
\text { correlation, } \%\end{array}$ & $\begin{array}{l}\text { Minimum deviation from } \\
\text { correlation, } \%\end{array}$ \\
\hline Lockhart and Martinelli50 & 26.20 & 46.16 & 4.43 \\
\hline Mishima and Hibiki ${ }^{52}$ & 30.23 & -8.80 & -53.70 \\
\hline Zhang et al. ${ }^{54}$ & 30.41 & -8.81 & -53.72 \\
\hline Lee and $\mathrm{Lee}^{53}$ & 27.41 & 7.34 & -53.80 \\
\hline Müller-Steinhagen and $\mathrm{Heck}^{51}$ & 34.50 & 6.78 & -67.51 \\
\hline Saisorn and Wongwises ${ }^{8}$ & 80.25 & 110.89 & 43.98 \\
\hline Hwang and $\mathrm{Kim}^{55}$ & 23.02 & -0.80 & -38.2 \\
\hline $\mathrm{Li}$ and $\mathrm{Wu}^{56}$ & 24.48 & 44.35 & 3.62 \\
\hline Kawahara et al. ${ }^{11}$ & 55.0 & 100.52 & 32.82 \\
\hline Saisorn and Wongwises ${ }^{9}$ & 62.63 & 82.74 & 21.008 \\
\hline Kim and Mudawar ${ }^{57}$ & 10.62 & 53.50 & -16.61 \\
\hline New correlation & 10.51 & 22.50 & -15.38 \\
\hline
\end{tabular}


Fig. 8 represents the comparisons of simulated data with other existing correlations plotted within \pm 30 $\%$. The mean absolute errors (MAE) between simulated data and existing correlations in literature are calculated and presented in Table 5. The mean absolute error is defined as:

MAE $=\frac{1}{N} \sum \frac{\left|\mathrm{d} p / \mathrm{d} Z_{f, P R E D}-\mathrm{d} p / \mathrm{d} Z_{f, S I M}\right|}{\mathrm{d} p / \mathrm{d} Z_{f, S I M}} \cdot 100 \%$

where $N$ is the number of data points.

The correlations of Lockhart and Martinelli ${ }^{50}$, Saisorn and Wongwises ${ }^{8,9}, \mathrm{Li}$ and $\mathrm{Wu}^{56}$, Kawahara et al. ${ }^{11}$, Kim and Mudawar ${ }^{57}$ over-predicted most of the simulated data, while the correlations of Mishima and Hibiki ${ }^{52}$, Zhang et al. ${ }^{54}$, Lee and $\mathrm{Lee}^{53}$, Müller-Steinhagen and $\mathrm{Heck}^{51}$, Hwang and $\mathrm{Kim}^{55}$ under-predicted most of the simulated data, as shown in Table 5. The trends of frictional pressure drop obtained from correlations of Mishima and Hibiki ${ }^{52}$, Zhang et al. ${ }^{54}$ and Lee and Lee ${ }^{53}$ are similar as shown in Fig. 8 (b-d). Most of the evaluated correlations are found inconsistent with the simulated results for slug flow regime. The simulated results display reasonable agreement with $\mathrm{Kim}$ and $\mathrm{Mu}-$ dawar's ${ }^{57}$ correlation, followed by correlations of Hwang and $\mathrm{Kim}^{55}$ and $\mathrm{Li}$ and $\mathrm{Wu}^{56}$ as shown in Fig. $8(\mathrm{a}, \mathrm{g}, \mathrm{h}$, and $\mathrm{k})$. The reason for reasonable agreement of these correlations can be expected as these authors have incorporated the contribution of the interfacial forces in terms of some dimensionless numbers in their expression of the $C$-parameter. However, maximum and minimum deviations observed between simulated and predicted data using these correlations are very high and beyond the range of $\pm 30 \%$ as shown in the Table 5 .

\section{New correlation for frictional pressure drop} for the slug flow

The attempt is made to develop separated flow model exclusively for slug flow regime incorporating fluid properties such as surface tension and viscosity in terms of dimensionless numbers in the $C$-parameter to capture frictional pressure drop profile precisely. In order to fit the entire simulated data of slug flow regime, a new correlation is developed on the basis of separated flow model by modifying $C$-parameter proposed in Kawahara et al. ${ }^{11}$ The new correlation is as follows:

$$
C=1.1 B o^{-0.05} \operatorname{Re}_{l}^{0.05} \mathrm{We}_{g}^{-0.12}
$$

The proposed correlation predicts entire simulated data of the present investigation in the slug flow regime within MAE of $10 \%$. The maximum and minimum deviation of errors between data obtained from simulation and proposed correlation is
$+22.5 \%$ and $-15.4 \%$, respectively as given in Table 5 and Fig. 9. Both maximum and minimum deviations of errors are observed at flow conditions close to boundary region of slug flow regime. Furthermore, the present correlation allowed capturing the trends of variation in liquid properties much more efficiently than other correlations.

\section{Effect of surface tension and viscosity on slug flow hydrodynamics}

A number of simulations with varying liquid properties in microchannel are performed. The influence of variations in liquid viscosity and surface tension on the hydrodynamics of slug flow in adiabatic T-junction square microchannel is investigated. The increasing liquid viscosity resulted in the increase in capillary number and favoured the bubble formation via shearing regime (Fig. 10). At lower surface tension, the bubble formation followed shearing regime, while, at higher values of surface tension, bubbles are formed via squeezing regime, as illustrated in Fig. 11. The stratified flow is observed as surface tension approached zero. The bubbles formed are more uniformly sized at higher surface tension in comparison to lower surface tension value. Since the shearing flow regime has lower mixing as compared to squeezing regime, mixing is decreased in fluids with low surface tension and high viscosity. Furthermore, the two-phase frictional pressure drop varied linearly with increase in liquid viscosity, as shown in Fig. 12a. However, twophase frictional pressure drop slightly varied with increasing the surface tension (Fig. 12b). A sharp fall in two-phase frictional pressure drop is observed as flow regimes deviate from slug flow to stratified flow. The trends of two-phase frictional pressure drop by varying liquid properties are also compared using a newly developed correlation (Fig. 12), which is able to capture data trends very efficiently, except at lower surface tension close to zero.

Hence, the present correlation can be used for prediction of frictional pressure drop in gas liquid two-phase slug flow regime in square and other geometric shaped microfluidic devices. Furthermore, the present correlation can be applied for prediction of frictional pressure drop in slug flow with non-uniform slug lengths.

\section{Conclusions}

The gas liquid two-phase slug flows in adiabatic T-junction square microchannel $\left(d_{\mathrm{H}}=1 \mathrm{~mm}\right)$ have been investigated using volume of fluid (VOF) technique with ANSYS FLUENT software. The bubble dynamics and two-phase frictional pressure 
a)

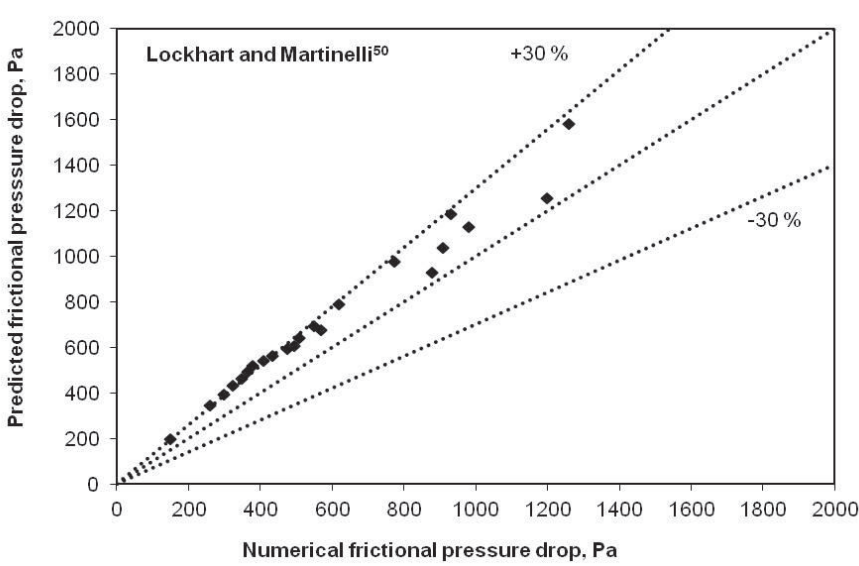

b)

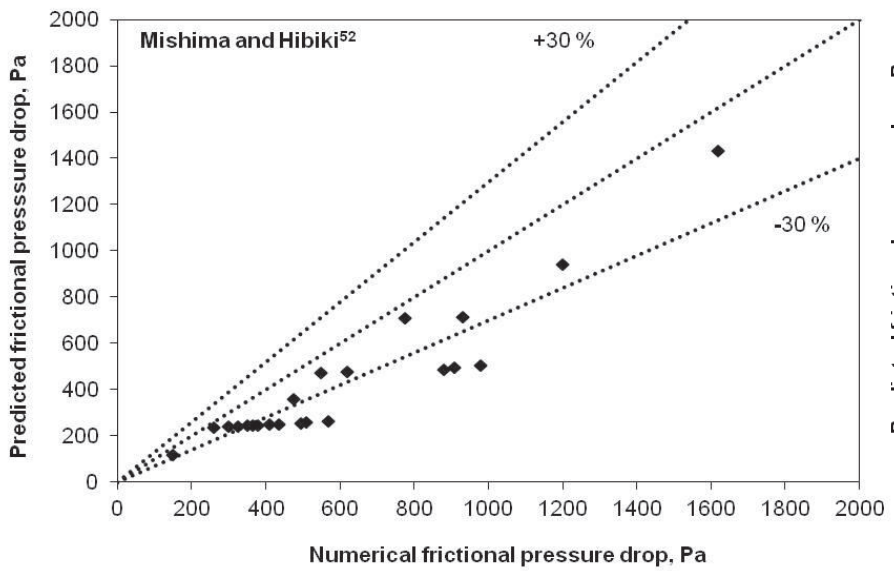

c)

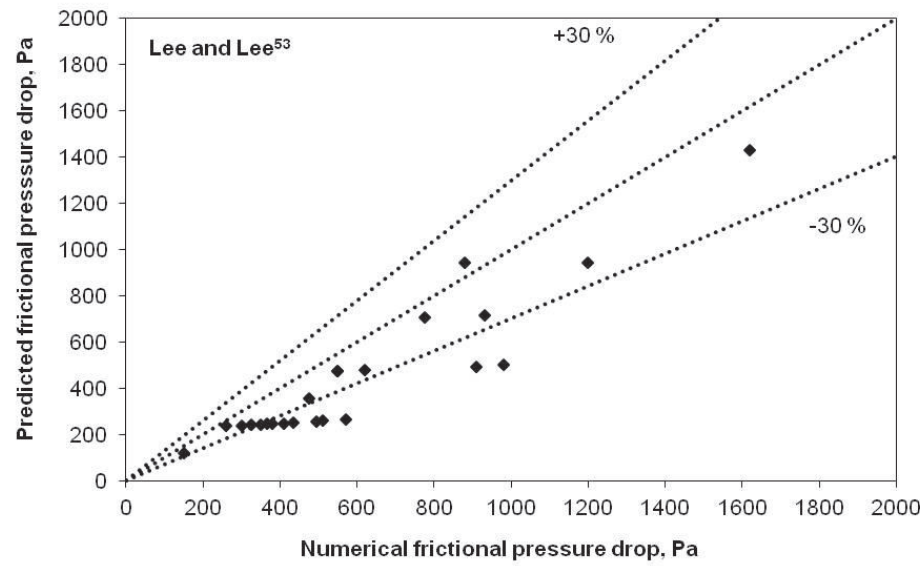

d)

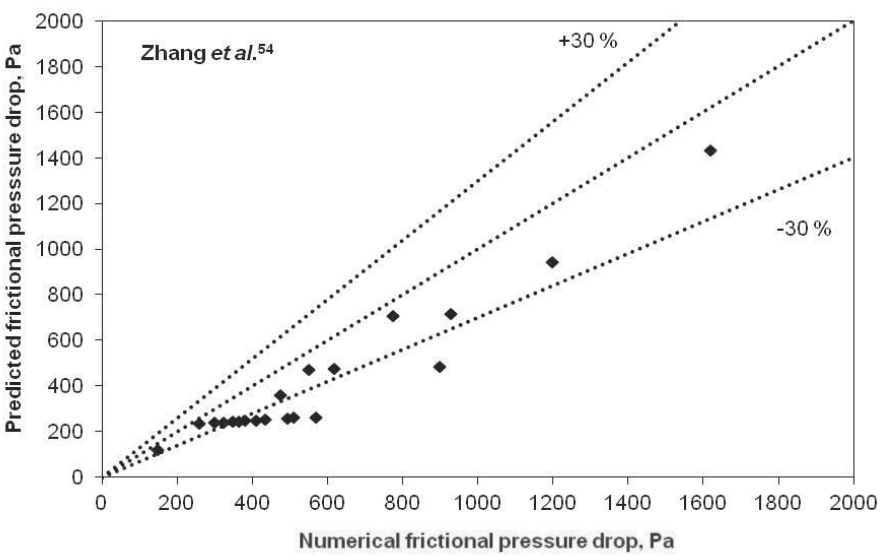

e)

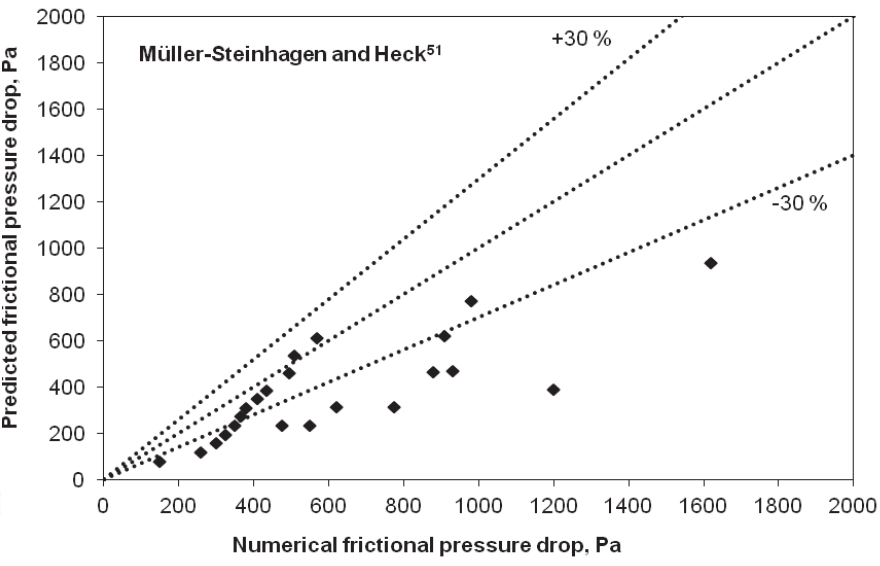

f)

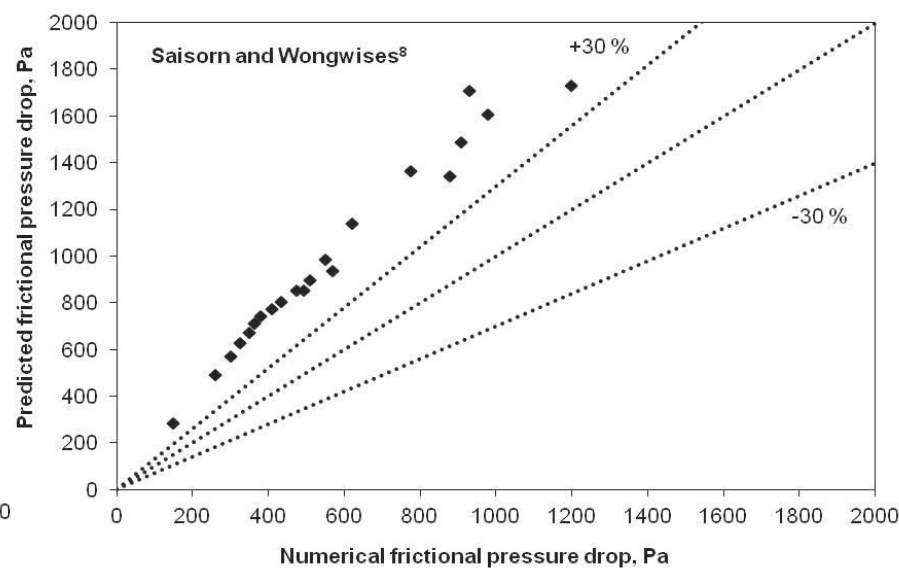


g)

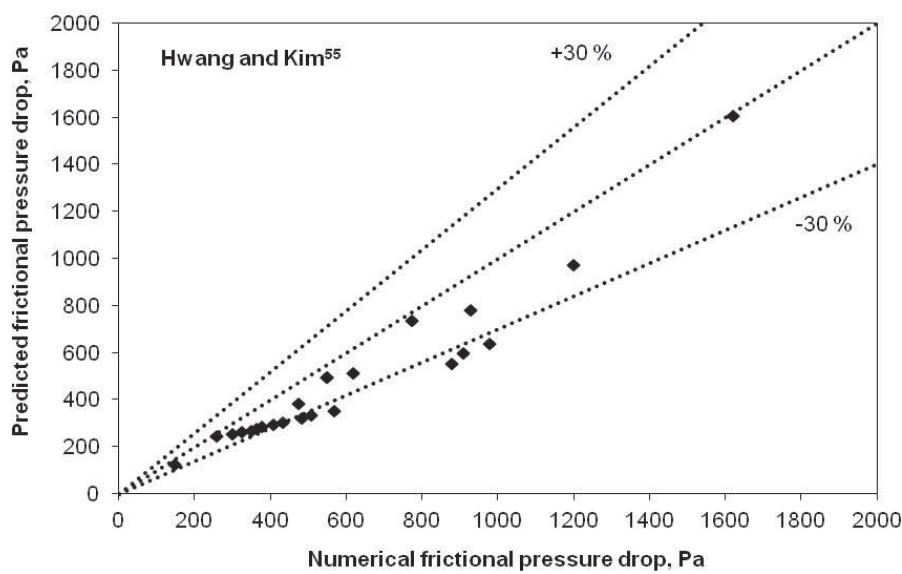

h)

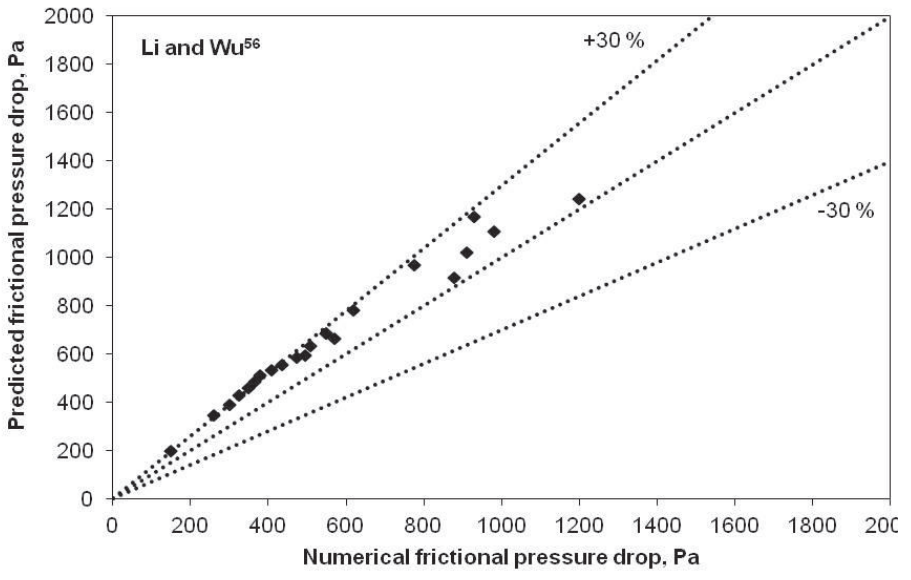

j)

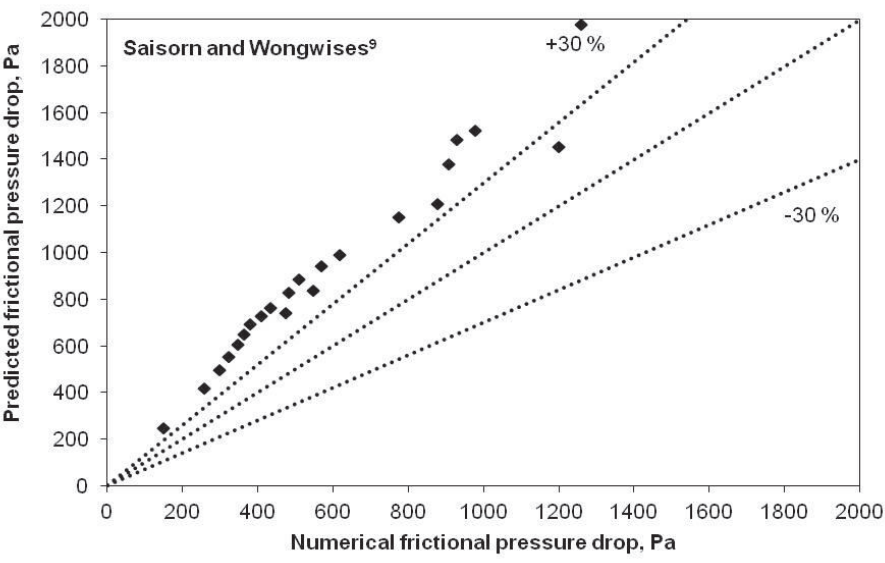

k)

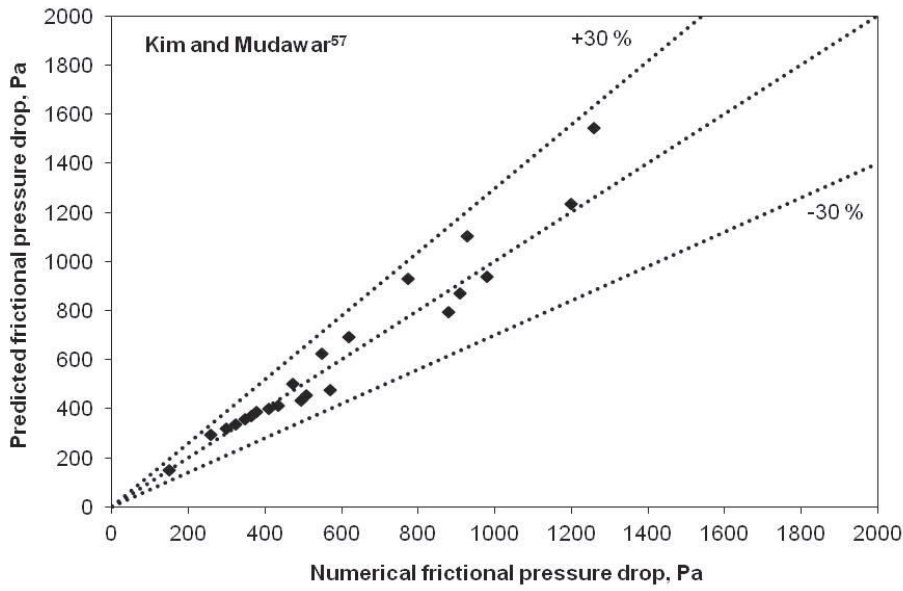

i)

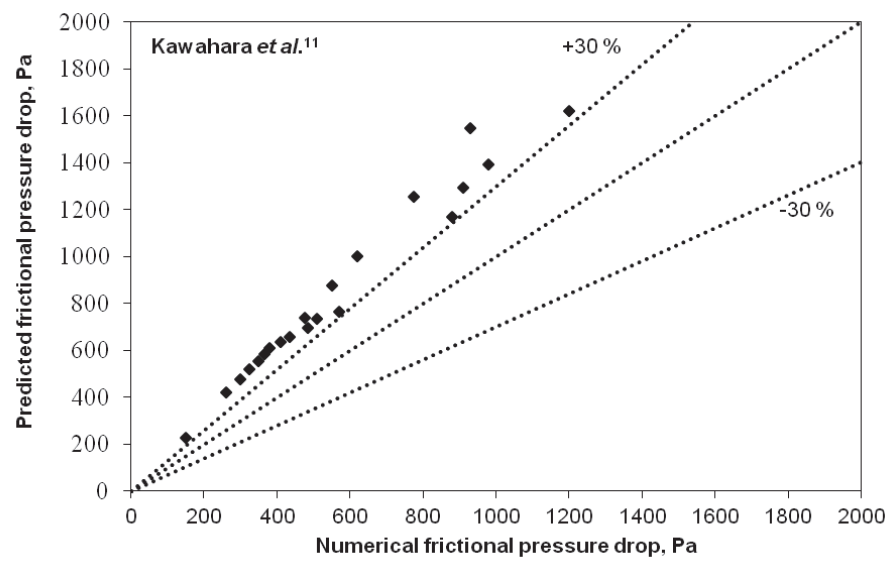

Fig. 8 - Evaluation of simulated two-phase frictional pressure drop for slug flow in adiabatic T-shaped square microchannel with prediction by different separated flow models (a) Lockhart and Martinelli (b) Mishima and Hibiki (c) Lee and Lee (d) Zhang et al. (e) Müller-Steinhagen and Heck (f) Saisorn and Wongwises (2008) (g) Hwang and Kim (h) Li and Wu (i) Kawahara et al. (2009) (j) Saisorn and Wongwises (2010) (k) Kim and Mudawar 


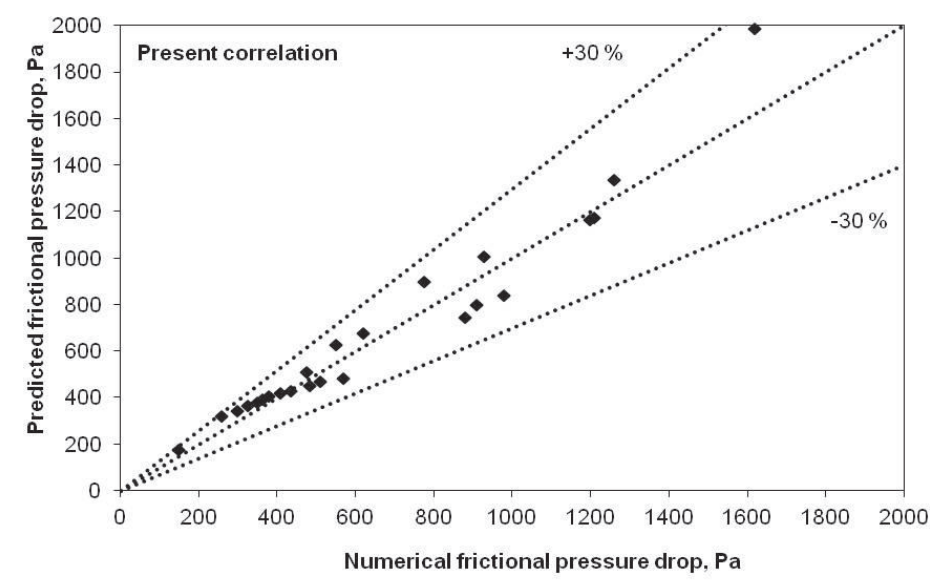

Fig. 9 - Evaluation of simulated two-phase frictional pressure drop for slug flow in adiabatic T-shaped square microchannel with prediction by proposed new correlation based on separated flow model

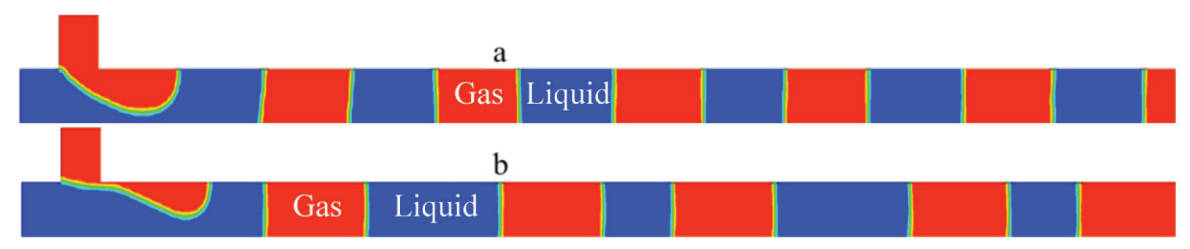

Fig. 10 - Effect of liquid viscosity on the dynamics of bubble formation for slug flow in adiabatic T-shaped square microchannel a) $\mu_{l}=0.00025 \mathrm{~kg} \mathrm{~m}^{-1} \mathrm{~s}^{-1}$; b) $\mu_{L}=0.006$ $\mathrm{kg} \mathrm{m}^{-1} \mathrm{~s}^{-1}$; at $U_{g}=0.1 \mathrm{~m} \mathrm{~s}^{-1}$ and $U_{l}=0.1 \mathrm{~m} \mathrm{~s}^{-1}$ (Red: gas phase; Blue: liquid phase)

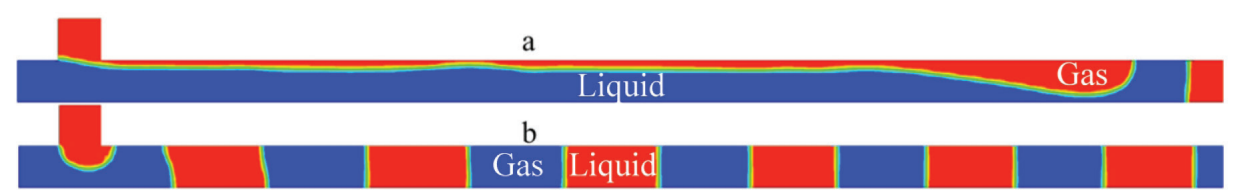

Fig. 11 - Effect of surface tension on the dynamics of bubble formation for slug flow in adiabatic T-shaped square microchannel a) $\sigma=0.02 \mathrm{~N} \mathrm{~m}^{-1}$; b) $\sigma=0.18 \mathrm{~N} \mathrm{~m}^{-1}$; at $U_{g}=0.1 \mathrm{~m} \mathrm{~s}^{-1}$ and $U_{l}=0.1 \mathrm{~m} \mathrm{~s}^{-1}$ (Red: gas phase; Blue: liquid phase)

drop were studied. At low capillary number (low liquid velocity), bubbles formed in accordance with the squeezing regime; while at high capillary number (high liquid velocity) the formation of bubbles followed the shearing regime. From the numerical studies, it is observed that mixing is higher in squeezing regime as compared to shearing regime. Further, the bubble length is found as a function of diameter and ratio of gas to liquid flow rates, and displayed a similar trend as predicted by the correlations of Qian and Lawal ${ }^{17}$, van Steijn et al..$^{44}$, Pohorecki and Kula ${ }^{48}$, Sobieszuk et al. ${ }^{49}$ and Kawahara et al. ${ }^{12}$ The two-phase frictional pressure drop for slug flow regimes has been investigated and evaluated with existing separated flow models reported in literature. Most of the evaluated correlations were found to be inconsistent with the simulated data for slug flow regime. However, cor- relations of Kim and Mudawar ${ }^{57}$, Hwang and $\mathrm{Kim}^{55}$ and $\mathrm{Li}$ and $\mathrm{Wu}^{56}$ are in good agreement with simulated data. In order to fit the entire two-phase frictional pressure drop data for the slug flow regime of the present investigation, a new correlation has been developed on the basis of separated flow model by modifying $C$-parameter of Kawahara et al. ${ }^{11}$ The newly developed correlation predicted simulated two-phase frictional pressure drop data of slug flow region satisfactorily with MAE of $10 \%$. Additionally, simulations were also performed to investigate the effect of fluid properties on slug flow hydrodynamics. The higher liquid viscosity and lower surface tension value resulted in bubble formation via shearing regime. The two-phase frictional pressure drop varied linearly with increase in liquid viscosity, while it was affected slightly with increase in surface tension, except at values close to zero. In 


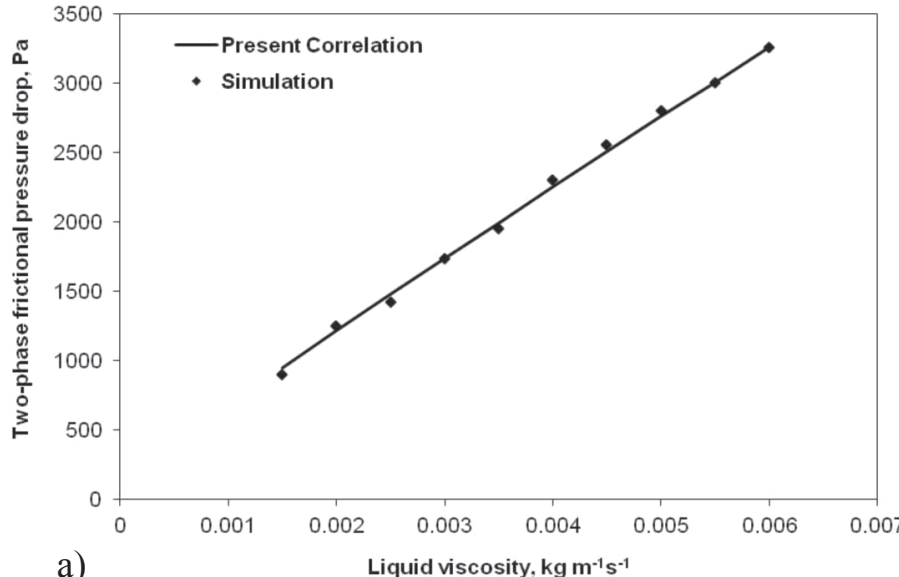

a)

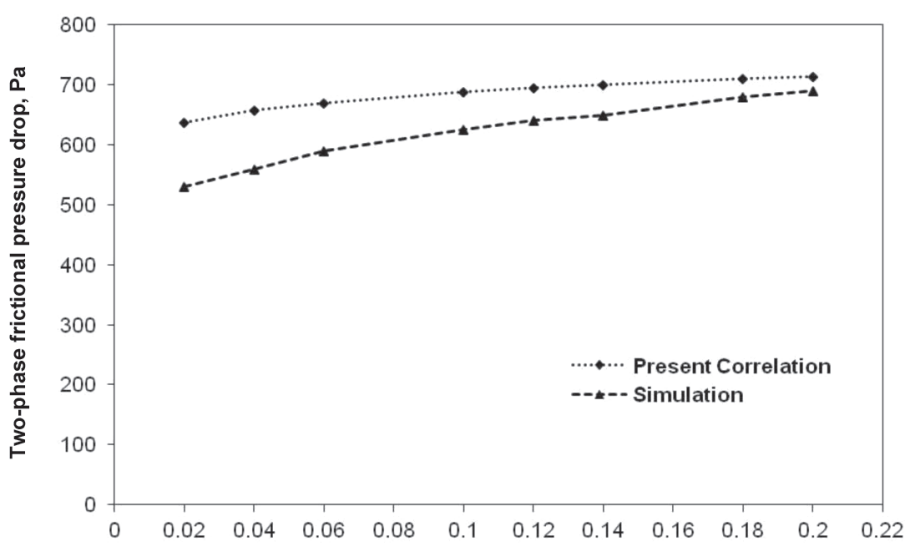

b)

Surface tension, $\mathrm{N} \mathrm{m}^{-1}$

Fig. 12 - Influence of (a) liquid viscosity (b) surface tension on the two-phase frictional pressure drop for slug flow in adiabatic T-shaped square microchannel at $U_{g}=0.1 \mathrm{~m} \mathrm{~s}^{-1}$ and $U_{l}=0.1 \mathrm{~m} \mathrm{~s}^{-1}$

addition, this study indicates that VOF method is an efficient tool for realizing and analysing slug flow in microfluidic devices.

\section{ACKNOWLEDGEMENT}

The authors would like to acknowledge the financial support from the Ministry of Human Resource Development, Government of India and Motilal Nehru National Institute of Technology Allahabad, (India) to carry out the work.

\section{Nomenclatures}

Bo - Bond number $\left(\frac{g\left(\rho_{l}-\rho_{g}\right) d^{2}}{\sigma}\right)$

Ca - Capillary number $\left(\frac{\mu U}{\sigma}\right)$

Re - Reynolds number $\left(\frac{\rho U d}{\mu}\right)$

$S u$ - Suratman number $\left(\frac{\rho \sigma d_{\mathrm{H}}}{\mu^{2}}\right)$
We - Weber number $\left(\frac{\rho U^{2} d}{\sigma}\right)$

C - parameter in separated flow model

$d$ - diameter of channel, $\mathrm{m}$

$P \quad$ - pressure, $\mathrm{Pa}$

$L \quad$ - length, $\mathrm{m}$

$U$ - velocity, $\mathrm{m} \mathrm{s}^{-1}$

$x \quad$ - mass quality

$X^{2}$ - Martinelli parameter

$Z$ - distance, $m$

\section{Greek letters}

$\alpha$ - volume fraction

$\varepsilon \quad-$ hold up

$\sigma \quad$ - surface tension

$\mu \quad-$ viscosity

$\rho-$ density

$\phi \quad-$ two-phase frictional multiplier

\section{Subscript and superscript}

b - bubble

- frictional

g - gas

go - gas only (total flow is assumed for gas only)

1 - liquid

lo - liquid only (total flow is assumed for liquid only)

$\mathrm{H}$ - hydraulic

s $\quad-$ slug

TP - two-phase

\section{References}

1. Zhao, C.-X., Middelberg, A. P. J., Two-phase microfluidic flows, Chem. Eng. Sci. 66 (2011) 1394. doi: https://doi.org/10.1016/j.ces.2010.08.038

2. Günther, A., Jensen K. F., Multiphase microfluidics: From flow characteristics to chemical and material synthesis, Lab chip. 6 (2006) 1487. doi: https://doi.org/10.1039/B609851G

3. Santos, R. M., Kawaji, M., Developments on wetting effects in microfluidic slug flow, Chem. Eng. Comm. 199 (2012) 1626. doi: https://doi.org/10.1080/00986445.2012.660712

4. Triplett, K. A., Ghiaasiaan, S. M., Abdel-Khalik, S. I., Sadowski, D. L., Gas-liquid two phase flow in microchannels-Part I: two-phase flow patterns, Int. J. Multiphase Flow 25 (1999a) 377 doi: https://doi.org/10.1016/S0301-9322(98)00054-8

5. Triplett, K. A., Ghiaasiaan, S. M., Abdel-Khalik, S. I., Lemouel, A., McCord, B. N., Gas-liquid two-phase flow in microchannels Part II: void fraction and pressure drop, Int. J. Multiphase Flow 25 (1999b) 395. doi: https://doi.org/10.1016/S0301-9322(98)00055-X 
6. Kawahara, A., Chung, P. M.-Y., Kawaji, M., Investigation of two-phase flow pattern, void fraction and pressure drop in a microchannel, Int. J. Multiphase Flow 28 (2002) 1411. doi: https://doi.org/10.1016/S0301-9322(02)00037-X

7. Chung, P. M.-Y., Kawaji, M., The effect of channel diameter on adiabatic two-phase flow characteristics in microchannels, Int. J. of Multiphase Flow 30 (2004) 735. doi: https://doi.org/10.1016/j.ijmultiphaseflow.2004.05.002

8. Saisorn, S., Wongwises, S., Flow pattern, void fraction and pressure drop of two-phase air-water flow in a horizontal circular micro-channel, Exp. Thermal Fluid Sci. 32 (2008) 748 . doi: https://doi.org/10.1016/j.expthermflusci.2007.09.005

9. Saisorn, S., Wongwises, S., The effects of channel diameter on flow pattern void fraction and pressure drop of twophase air-water flow in circular micro-channels, Exp. Thermal Fluid Sci. 34 (2010) 454.

doi: https://doi.org/10.1016/j.expthermflusci.2009.02.006

10. Niu, H., Pan, L., Su, H., Wang, S., Flow pattern, pressure drop, and mass transfer in a gas-liquid concurrent twophase flow microchannel reactor, Ind. Eng. Chem. Res. 48 (3) (2009) 1621. doi: https://doi.org/10.1021/ie801095a

11. Kawahara, A., Sadatomi, M., Nei, K., Matsuo, H., Experimental study on bubble velocity, void fraction and pressure drop for gas-liquid two-phase flow in a circular microchannel, Int. J. Heat Fluid Flow 30 (2009) 831. doi: https://doi.org/10.1016/j.ijheatfluidflow.2009.02.017

12. Kawahara, A., Sadatomi, M., Nei, K., Matsuo, H., Characteristics of two-phase flows in a rectangular microchannel with a T-junction type gas-liquid mixer, Heat Trans. Eng. 32 (7-8) (2011) 585.

doi: https://doi.org/10.1080/01457632.2010.509752

13. Abadie, T., Aubin, J., Legendre, D., Xuereb, C., Hydrodynamics of gas-liquid Taylor flow in rectangular microchannels, Microfluid. Nanofluid. 12 (2012) 355. doi: https://doi.org/10.1007/s10404-011-0880-8

14. Taha, T., Cui, Z. F., Hydrodynamics of slug flow inside capillaries, Chem. Eng. Sci. 59 (2004) 1181. doi: https://doi.org/10.1016/j.ces.2003.10.025

15. Taha, T., Cui, Z. F., CFD modeling of slug flow inside square capillaries, Chem. Eng. Sci. 61 (2006a) 665. doi: https://doi.org/10.1016/j.ces.2005.07.023

16. Taha, T., Cui, Z. F., CFD modeling of slug flow in vertical tubes, Chem. Eng. Sci. 61 (2006b) 676. doi: https://doi.org/10.1016/j.ces.2005.07.022

17. Qian, D., Lawal A., Numerical study on gas and liquid slugs for Taylor flow in a T-junction microchannel, Chem. Eng. Sci. 61 (2006) 7609.

doi: https://doi.org/10.1016/j.ces.2006.08.073

18. Kumar, V., Vashisth, S., Hoarau, Y., Nigam, K. D. P., Slug flow in curved microreactors: Hydrodynamic study, Chem. Eng. Sci. 62 (2007) 7494. doi: https://doi.org/10.1016/j.ces.2007.06.026

19. Guo, F., Chen, B., Numerical study on Taylor bubble formation in a microchannel T-junction using VOF method, Microgravity Sci. Tech. 21 (Suppl. 1) (2009) S51 doi: https://doi.org/10.1007/s12217-009-9146-4

20. Gupta, R., Fletcher, D. F., Haynes, B. S., On the CFD modelling of Taylor flow in microchannels, Chem. Eng. Sci. 64 (2009) 2941. doi: https://doi.org/10.1016/j.ces.2009.03.018

21. Santos, R. M., Kawaji, M., Numerical modeling and experimental investigation of gas-liquid slug formation in a microchannel T-junction, Int. J. Multiphase Flow. 36 (2010) 314. doi: https://doi.org/10.1016/j.ijmultiphaseflow.2009.11.009
22. Santos, R. M., Kawaji, M., Gas-liquid slug formation at a rectangular microchannel T-junction: A CFD benchmark case, Cent. Eur. J. Eng. 1 (4) (2011) 341. doi: https://doi.org/10.2478/s13531-011-0038-1

23. Van Baten, J. M. Krishna R., CFD simulation of mass transfer from Taylor bubbles rising in circular capillaries, Chem. Eng. Sci. 59 (2004) 2535. doi: https://doi.org/10.1016/j.ces.2004.03.010

24. Liu, D., Wang, S., Hydrodynamics of Taylor flow in noncircular capillaries, Chem. Eng. Proc. 47 (2008) 2098. doi: https://doi.org/10.1016/j.cep.2007.10.025

25. Liu, D., Wang, S., Gas-liquid mass transfer in Taylor flow through circular capillaries, Ind. Eng. Chem. Res. 50 (2011) 2323. doi: https://doi.org/10.1021/ie902055p

26. Talimi, V., Muzychka, Y. S., Kocabiyik, S., Slug flow heat transfer in square microchannels, Int. J. Heat Mass Trans. 62 (2013) 752. doi: https://doi.org/10.1016/j.ijheatmasstransfer.2013.03.035

27. Akbar, M. K., Ghiaasiaan, S. M., Simulation of Taylor flow in capillaries based on the Volume-of-Fluid technique, Ind. Eng. Chem. Res. 45 (2006) 5396. doi: https://doi.org/10.1021/ie0601551

28. Shao, N., Salman, W., Gavriilidis, A., Angeli, P., CFD simulations of the effect of inlet conditions on Taylor flow formation, Int. J. Heat Fluid Flow. 29 (2008) 1603. doi: https://doi.org/10.1016/j.ijheatfluidflow.2008.06.010

29. Dai, L., Cai, W., Xin, F., Numerical study on bubble formation of a gas-liquid flow in a T-junction microchannel, Chem. Eng. Tech. 32 (12) (2009) 1984. doi: https://doi.org/10.1002/ceat.200900351

30. Goel, D., Buwa, V. V., Numerical simulations of bubble formation and rise in microchannels, Ind. Eng. Chem. Res. 48 (2009) 8109. doi: https://doi.org/10.1021/ie800806f

31. Raj, R., Mathur, N. Buwa, V. V., Numerical simulations of liquid-liquid flows in microchannels, Ind. Eng. Chem. Res. 49 (21) (2010) 10606. doi: https://doi.org/10.1021/ie100626a

32. Kashid, M. N., Renken, A., Kiwi-Minsker, L., CFD modelling of liquid-liquid multiphase microstructured reactor: Slug flow generation, Chem. Eng. Res. Des. 88 (2010) 362. doi: https://doi.org/10.1016/j.cherd.2009.11.017

33. Asadolahi, A. N., Gupta, R., Fletcher, D. F., Haynes, B. S., CFD approaches for the simulation of hydrodynamics and heat transfer in Taylor flow, Chem. Eng. Sci. 66 (2011) 5575 . doi: https://doi.org/10.1016/j.ces.2011.07.047

34. Sivasamy, J., Wong, T. N., Nguyen, N. T., Kao, L. T. H., An investigation on the mechanism of droplet formation in a microfluidic T-junction, Microfluid. Nanofluid. 11 (2011) 69. doi: https://doi.org/10.1007/s10404-011-0767-8

35. Li, X. B., Li, F. C., Yang, J. C., Kinoshita, H., Oishi, M., Oshima, M., Study on the mechanism of droplet formation in T-junction microchannel, Chem. Eng. Sci. 69 (2012). doi: https://doi.org/10.1016/j.ces.2012.01.054

36. Horgue, P., Augier F., Quintard M., Prata, M., A suitable parameterization to simulate slug flows with the Volume-of-Fluid method, Comptes. Rend. Mecan. 340 (2012) 411. doi: https://doi.org/10.1016/j.crme.2012.01.003

37. Talimi, V., Muzychka, Y. S., Kocabiyik, S., Numerical simulation of the pressure drop and heat transfer of two phase slug flows in microtubes using moving frame of reference technique, Int. J. Heat Mass Trans. 55 (2012) 6463. doi: https://doi.org/10.1016/j.ijheatmasstransfer.2012.06.044 
38. Hoang, A. D., van Steijn, V., Portela, L. M., Kreutzer, M. T. Kleijn, C. R., Benchmark numerical simulations of segmented two-phase flows in microchannels using the Volume of Fluid method, Comp. Fluids. 86 (2013) 28. doi: https://doi.org/10.1016/j.compfluid.2013.06.024

39. Kang, S., Zhou, B., Numerical study of bubble generation and transport in a serpentine channel with a T-junction, Int. J. Hyd. Energy. 39 (2014) 2325 doi: https://doi.org/10.1016/j.ijhydene.2013.11.115

40. Chandra, A. K., Kishor, K., Mishra, P. K., Alam, M. S., Numerical investigations of two-phase flows through enhanced microchannels, Chem. and Biochem. Eng. Quart. 30 (2) (2016) 149.

doi: https://doi.org/10.15255/CABEQ.2015.2289

41. Hirt, C. W., Nichols, B. D., Volume of fluid (VOF) method for the dynamics of free boundaries, J. Comp. Phys. 39 (1981) 201. doi: https://doi.org/10.1016/0021-9991(81)90145-5

42. Brackbill, J. U., Kothe, D. B., Zemach C., A continuum method for modeling surface tension, J. Computational Phys. 100 (1992) 335. doi: https://doi.org/10.1016/0021-9991(92)90240-Y

43. Garstecki, P., Fuerstman, M. J., Stone, H. A., Whitesides, G. M., Formation of droplets and bubbles in a microfluidic T-junction - scaling and mechanism of break-up, Lab Chip. 6 (2006) 437. doi: https://doi.org/10.1039/b510841a

44. Van Steijn V., Kreutzer, M. T., Kleijn, C. R., $\mu$-PIV study of the formation of segmented flow in microfluidic T-junctions, Chem. Eng. Sci. 62 (2007) 7505. doi: https://doi.org/10.1016/j.ces.2007.08.068

45. Bercic, G., Pintar, A., The role of gas bubbles and liquid slug lengths on mass transport in the Taylor flow through capillaries, Chem. Eng. Sci. 52 (1997) 3709. doi: https://doi.org/10.1016/S0009-2509(97)00217-0

46. Vandu, C. O., Liu, H., Krishna, R., Mass transfer from Taylor bubbles rising in single capillaries, Chem. Eng. Sci. 60 (2005) 6430.

doi: https://doi.org/10.1016/j.ces.2005.01.037

47. Yue, J., Chen, G., Yuan, Q., Luo, L., Gonthier, Y., Hydrodynamics and mass transfer characteristics in gas-liquid flow through a rectangular microchannel, Chem. Eng. Sci. 62 (2007) 2096.

doi: https://doi.org/10.1016/j.ces.2006.12.057

48. Pohorecki, R. Kula, K., A simple mechanism of bubble and slug formation in Taylor flow in microchannels, Chem. Eng. Res. Des. 86 (2008) 997. doi: https://doi.org/10.1016/j.cherd.2008.03.013
49. Sobieszuk, P., Cygański, P., Pohorecki, R., Bubble lengths in the gas-liquid Taylor flow in microchannels, Chem. Eng. Res. Des. 88 (2010) 263. doi: https://doi.org/10.1016/j.cherd.2009.07.007

50. Lockhart, R. W., Martinelli, R. C., Proposed correlation of data for isothermal two-phase, two-component flow in pipes, Chem. Eng. Prog. 45 (1949) 39.

51. Müller-Steinhagen, H., Heck, K., A simple friction pressure drop correlation for two-phase flow in pipes, Chem. Eng. Process. 20 (1986) 297. doi: https://doi.org/10.1016/0255-2701(86)80008-3

52. Mishima, K., Hibiki, T., Some characteristics of air-water two-phase flow in small diameter vertical tubes, Int. J. Multiphase Flow. 22 (1996) 703. doi: https://doi.org/10.1016/0301-9322(96)00010-9

53. Lee, H. J., Lee, S. Y., Pressure drop correlations for twophase flow within horizontal rectangular channels with small heights, Int. J. Multiphase Flow. 27 (2001) 783. doi: https://doi.org/10.1016/S0301-9322(00)00050-1

54. Zhang, W., Hibiki, T., Mishima, K., Correlations of twophase frictional pressure drop and void fraction in mini-channel, Int. J. Heat Mass Trans. 53 (2010) 453. doi: https://doi.org/10.1016/j.ijheatmasstransfer.2009.09.011

55. Hwang, Y. W., Kim, M. S., The pressure drop in microtubes and the correlation development, Int. J. Heat Mass Trans. 49 (2006) 1804.

doi: https://doi.org/10.1016/j.ijheatmasstransfer.2005.10.040

56. $L i, W$., $W u, Z$., A general correlation for adiabatic two-phase pressure drops in micro/mini-channels. Int. J. Heat Mass Trans. 53 (2010) 2732. doi: https://doi.org/10.1016/j.ijheatmasstransfer.2010.02.029

57. Kim, S.-M., Mudawar, I., Universal approach to predicting two-phase frictional pressure drop for adiabatic and condensing mini/micro-channel flows, Int. J. of Heat Mass Trans. 55 (2012) 3246. doi: https://doi.org/10.1016/j.ijheatmasstransfer.2012.02.047

58. Kreutzer, M. T., Kapteijn, F., Moulijn, J. A., Internal and interfacial effects on pressure drop of Taylor flow in capillaries, AIChE J. 51 (9) (2005) 2428. doi: https://doi.org/10.1002/aic.10495

59. Gupta, R., Fletcher, D. F., Haynes, B. S., CFD modelling of flow and heat transfer in the Taylor flow regime, Chem. Eng. Sci. 65 (2010) 2094. doi: https://doi.org/10.1016/j.ces.2009.12.008 